\title{
The Science of Monetary Policy: A New Keynesian Perspective*
}

\author{
Richard Clarida, Jordi Gali, and Mark Gertler ${ }^{\dagger}$
}

\author{
April 1999 (first draft: September 1997)
}

\begin{abstract}
This paper reviews the recent literature on monetary policy rules. We exposit the monetary policy design problem within a simple baseline theoretical framework. We then consider the implications of adding various real world complications. Among other things, we show that the optimal policy implicitly incorporates inflation targeting. We also characterize the gains from making credible commitments to fight inflation. In contrast to conventional wisdom, we show that gains from commitment may emerge even if the central bank is not trying to inadvisedly push output above its natural level. We also consider the implications of frictions such as imperfect information.
\end{abstract}

Keywords: Monetary Policy, Credibility, Stabilization, New Keynesian models

JEL Classification: E0, E5

${ }^{*}$ Forthcoming in the Journal of Economic Literature. Thanks to Ben Bernanke, Bob King, Ben McCallum, Albert Marcet, Rick Mishkin, Athanasios Orphanides, Glenn Rudebusch, Chris Sims, Lars Svensson, Andres Velasco, and several anonymous referees for helpful comments, and to Tommaso Monacelli for excellent research assistance. The second and third authors are grateful to the C.V. Starr Center for Applied Economics (Galí and Gertler) and CREI (Galí) for financial support.

${ }^{\dagger}$ Clarida: Columbia University and NBER; Galí: New York University, Universitat Pompeu Fabra, CEPR, and NBER; Gertler: New York University and NBER. Please send any correspondence to Mark Gertler at Dept. of Economics, NYU, 269 Mercer St., New York, N.Y., 10003. e-mail: mark.gertler@econ.nyu.edu 
"Having looked at monetary policy from both sides now, I can testify that central banking in practice is as much art as science. Nonetheless, while practicing this dark art, I have always found the science quite useful". ${ }^{1}$

\section{Alan S. Blinder}

\section{Introduction}

There has been a great resurgence of interest in the issue of how to conduct monetary policy. One symptom of this phenomenon is the enormous volume of recent working papers and conferences on the topic. Another is that over the past several years many leading macroeconomists have either proposed specific policy rules or have at least staked out a position on what the general course of monetary policy should be. John Taylor's recommendation of a simple interest rate rule (Taylor, 1993a) is a well known example. So too is the recent widespread endorsement of inflation targeting (e.g., Ben Bernanke and Frederic Mishkin, 1997).

Two main factors underlie this rebirth of interest. First, after a long period of near exclusive focus on the role of non-monetary factors in the business cycle, a stream of empirical work beginning in the late 1980s has made the case that monetary policy significantly influences the short term course of the real economy. ${ }^{2}$

\footnotetext{
1 "What Central Bankers Can Learn from Academics and Vice-Versa," Journal of Economic Perspectives 11, Spring 1997, p. 17.

${ }^{2}$ Examples include Romer and Romer (1988), Bernanke and Blinder (1992), Gali (1992), Bernanke and Mihov (1997a), Christiano, Eichenbaum and Evans $(1996,1998)$ and Leeper, Sims and Zha (1996). Much of the literature has focused on the effects of monetary policy shocks. Bernanke, Gertler and Watson (1997) present evidence that suggests that the monetary
} 
The precise amount remains open to debate. On the other hand, there now seems broad agreement that the choice of how to conduct monetary policy has important consequences for aggregate activity. It is no longer an issue to down-play.

Second, there has been considerable improvement in the underlying theoretical frameworks used for policy analysis. To provide theoretical underpinnings, the literature has incorporated the techniques of dynamic general equilibrium theory pioneered in real business cycle analysis. A key point of departure from real business cycle theory (as we later make clear) is the explicit incorporation of frictions such as nominal price rigidities that are needed to make the framework suitable for evaluation of monetary policy.

This paper summarizes what we have learned from this recent research on monetary policy. We review the progress that has been made and also identify the central questions that remain. To organize the discussion, we exposit the monetary policy design problem in a simple theoretical model. We start with a stripped-down baseline model in order to characterize a number of broad principles that underlie optimal policy management. We then consider the implications of adding various real world complications. Finally, we assess how the predictions from theory square with policy-making in practice.

Throughout, we concentrate on expositing results that are robust across a wide variety of macroeconomic frameworks. As Ben McCallum (1997b) emphasizes, the key stumbling block for policy-formation is limited knowledge of the way the macroeconomy works. Results that are highly model-specific are of limited use. This literature, however, contains a number of useful principles about optimal policy that are reasonably general in applicability. In this respect there is a

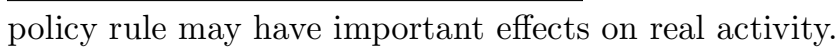


"science of monetary policy," as Alan Blinder suggests in the quote above. We provide support for this contention in the pages that follow.

At the same time, we should make clear that the approach we take is based on the idea that temporary nominal price rigidities provide the key friction that give rise to non-neutral effects of monetary policy. The propositions we derive are broadly applicable within this class of models. This approach has widespread support in both theoretical and applied work, as we discuss later ${ }^{3}$. There are, however, important strands of the literature that either reject the idea of nominal price rigidities (e.g., real business cycle theory) or focus on other types of nominal rigidities, such as frictions in money demand". For this reason, we append "New Keynesian Perspective" to the title. In particular, we wish to make clear that we adopt the Keynesian approach of stressing nominal price rigidities, but at the same time base our analysis on frameworks that incorporate the recent methodological advances in macroeconomic modeling (hence the term "New").

Section 2 lays out the formal policy problem. We describe the baseline theoretical model and the objectives of policy. Because we are interested in characterizing policy rules in terms of primitive factors, the model we use evolves from first principles. Though it is quite simple, it nonetheless contains the main ingredients of descriptively richer frameworks that are used for policy analysis. Within the model, as in practice (we argue), the instrument of monetary policy is a short term interest rate. The policy design problem then is to characterize how the interest rate should adjust to the current state of the economy.

\footnotetext{
${ }^{3}$ See, for example, the survey by Goodfriend and King (1997).

${ }^{4}$ See, for example, Christiano, Eichenbaum and Evans (1997). For an analysis of monetary policy rules in these kinds of models - know as "limited participation" frameworks - see Christiano and Gust (1999).
} 
An important complication is that private sector behavior depends on the expected course of monetary policy, as well as on current policy. The credibility of monetary policy thus becomes relevant, as a considerable contemporary literature has emphasized. ${ }^{5}$ At issue is whether there may be gains from enhancing credibility either by formal commitment to a policy rule or by introducing some kind of institutional arrangement that achieves roughly the same end. We address the issue by examining optimal policy for both cases: with and without commitment. Along with expositing traditional results, we also exposit some new results regarding the gains from commitment.

Section 3 derives the optimal policy rule in the absence of commitment. If for no other reason, this case is of interest because it captures reality: No major central bank makes any type of binding commitment over the future course of its monetary policy. A number of broad implications emerge from this baseline case. Among these: The optimal policy embeds inflation targeting in the sense that it calls for gradual adjustment to the optimal inflation rate. The implication for the policy rule is that the central bank should adjust the nominal short rate more than one-for-one with expected future inflation. That is, it should adjust the nominal rate sufficiently to alter the real rate (and thus aggregate demand) in the direction that is offsetting to any movement in expected inflation. Finally, how the central bank should adjust the interest rate in response to output disturbances depends critically on the nature of the disturbances: It should offset demand shocks but accommodate supply shocks, as we discuss.

Section 4 turns to the case with commitment. Much of the literature has emphasized that an inefficiently high steady state inflation rate may arise in the

\footnotetext{
${ }^{5}$ For a recent survey of the credibility literature, see Persson and Tabellini (1997).
} 
absence of commitment, if the central bank's target for real output exceeds the market clearing level. ${ }^{6}$ The gain from commitment then is to eliminate this inflationary bias. How realistic it is to presume that a perceptive central bank will try to inadvisedly reap short terms gains from pushing output above its natural level is a matter of recent controversy (e.g., Blinder, 1997, McCallum 1997a). We demonstrate, however, that there may be gains from commitment simply if current price setting depends on expectations of the future. In this instance, a credible commitment to fight inflation in the future can improve the current output/inflation trade-off that a central bank faces. Specifically, it can reduce the effective cost in terms of current output loss that is required to lower current inflation. This result, we believe, is new in the literature.

In practice, however, a binding commitment to a rule may not be feasible simply because not enough is known about the structure of the economy or the disturbances that buffet it. Under certain circumstances, however, a policy rule that yields welfare gains relative to the optimum under discretion may be well approximated by an optimal policy under discretion that is obtained by assigning a higher relative cost to inflation than the true social cost. A way to pursue this policy operationally is simply to appoint a central bank chairman with a greater distaste for inflation than society as a whole, as Kenneth Rogoff (1985) originally emphasized.

Section 5 considers a number of practical problems that complicate policymaking. These include: imperfect information and lags, model uncertainty and non-smooth preferences over inflation and output. A number of pragmatic issues

\footnotetext{
${ }^{6}$ The potential inflationary bias under discretion was originally emphasized by Kydland and Prescott (1977) and Barro and Gordon (1983).
} 
emerge, such as: whether and how to make use of intermediate targets, the choice of a monetary policy instrument, and why central banks appear to smooth interest rate changes. Among other things, the analysis makes clear why modern central banks (especially the Federal Reserve Board) have greatly downgraded the role of monetary aggregates in the implementation of policy. The section also shows how the recently advocated "opportunistic" approach to fighting inflation may emerge under a non-smooth policy objective function. The opportunistic approach boils down to trying to keep inflation from rising but allowing it to ratchet down in the event of favorable supply shocks.

As we illustrate throughout, the optimal policy depends on the degree of persistence in both inflation and output. The degree of inflation persistence is critical since this factor governs the output/inflation trade-off that the policy-maker faces. In our baseline model, persistence in inflation and output is due entirely to serially correlated exogenous shocks. In section 6 we consider a hybrid model that allows for endogenous persistence in both inflation and output. The model nests as special cases our forward looking baseline model and, also, a more traditional backward looking Keynesian framework, similar to the one used by Lars Svensson (1997a) and others.

Section 7 moves from theory to practice by considering a number of proposed simple rules for monetary policy, including the Taylor rule, and a forward looking variant considered by Clarida, Gertler and Gali $(1997,1998)$. Attention has centered around simple rules because of the need for robustness. A policy rule is robust if it produces desirable results in a variety of competing macroeconomic frameworks. This is tantamount to having the rule satisfy the criteria for good policy management that sections 2 through 6 establish. Further, U.S. monetary 
policy may be judged according to this same metric. In particular, the evidence suggests that U.S. monetary policy in the fifteen years or so prior to Paul Volcker did not always follow the principles we have described. Simply put, interest rate management during this era tended to accommodate inflation. Under Volcker and Greenspan, however, U.S. monetary policy adopted the kind of implicit inflation targeting that we argue is consistent with good policy management.

The section also considers some policy proposals that focus on target variables, including introducing formal inflation or price-level targets and nominal GDP targeting. There is in addition a brief discussion of the issue of whether indeterminacy may cause practical problems for the implementation of simple interest rate rules. Finally, there are concluding remarks in section 8 .

\section{A Baseline Framework for Analysis of Monetary Policy}

This section characterizes the formal monetary policy design problem. It first presents a simple baseline macroeconomic framework, and then describes the policy objective function. The issue of credibility is taken up next. In this regard, we describe the distinction between optimal policies with and without credible commitment - what the literature refers to as the cases of "rules versus discretion."

\subsection{A Simple Macroeconomic Framework}

Our baseline framework is a dynamic general equilibrium model with money and temporary nominal price rigidities. In recent years this paradigm has become 
widely used for theoretical analysis of monetary policy. ${ }^{7}$ It has much of the empirical appeal of the traditional IS/LM model, yet is grounded in dynamic general equilibrium theory, in keeping with the methodological advances in modern macroeconomics.

Within the model, monetary policy affects the real economy in the short run, much as in the traditional Keynesian IS/LM framework. A key difference, however, is that the aggregate behavioral equations evolve explicitly from optimization by households and firms. One important implication is that current economic behavior depends critically on expectations of the future course of monetary policy, as well as on current policy. In addition, the model accommodates differing views about how the macroeconomy behaves. In the limiting case of perfect price flexibility, for example, the cyclical dynamics resemble those of a real business cycle model, with monetary policy affecting only nominal variables.

Rather than work through the details of the derivation, which are readily available elsewhere, we instead directly introduce the key aggregate relationships. ${ }^{8}$ For convenience, we abstract from investment and capital accumulation. This abstraction, however, does not affect any qualitative conclusions, as we discuss. The model is as follows:

Let $y_{t}$ and $z_{t}$ be the stochastic components of output and the natural level of output, respectively, both in logs. ${ }^{9}$ The latter is the level of output that would arise if wages and prices were perfectly flexible. The difference between actual

\footnotetext{
${ }^{7}$ See, e.g, Goodfriend and King (1997), McCallum and Nelson (1997), Walsh (1998), and the references therein.

${ }^{8}$ See, for example, Yun (1996), Kimball (1995), King and Wolman (1995), Woodford (1996), and Bernanke, Gertler and Gilchrist (1998) for step-by-step derivations.

${ }^{9}$ By stochastic component, we mean the deviation from a deterministic long run trend.
} 
and potential output is an important variable in the model. It is thus convenient to define the "output gap" $x_{t}$ :

$$
x_{t} \equiv y_{t}-z_{t}
$$

In addition, let $\pi_{t}$ be the period $\mathrm{t}$ inflation rate, defined as the percent change in the price level from $t-1$ to $t$; and let $i_{t}$ be the nominal interest rate. Each variable is similarly expressed as a deviation from its long run level.

It is then possible to represent the baseline model in terms of two equations: an "IS" curve that relates the output gap inversely to the real interest rate; and a Phillips curve that relates inflation positively to the output gap.

$$
\begin{gathered}
x_{t}=-\varphi\left[i_{t}-E_{t} \pi_{t+1}\right]+E_{t} x_{t+1}+g_{t} \\
\pi_{t}=\lambda x_{t}+\beta E_{t} \pi_{t+1}+u_{t}
\end{gathered}
$$

where $g_{t}$ and $u_{t}$ are disturbances terms that obey, respectively:

$$
\begin{aligned}
& g_{t}=\mu g_{t-1}+\widehat{g}_{t} \\
& u_{t}=\rho u_{t-1}+\widehat{u}_{t}
\end{aligned}
$$

where $0 \leq \mu, \rho \leq 1$ and where both $\widehat{g}_{t}$ and $\widehat{u}_{t}$ are i.i.d. random variables with zero mean and variances $\sigma_{g}^{2}$ and $\sigma_{u}^{2}$, respectively.

Equation (2.1) is obtained by log-linearizing the consumption euler equation 
that arises from the household's optimal saving decision, after imposing the equilibrium condition that consumption equals output minus government spending. ${ }^{10}$ The resulting expression differs from the traditional IS curve mainly because current output depends on expected future output as well as the interest rate. Higher expected future output raises current output: Because individuals prefer to smooth consumption, expectation of higher consumption next period (associated with higher expected output) leads them to want to consume more today, which raises current output demand. The negative effect of the real rate on current output, in turn, reflects intertemporal substitution of consumption. In this respect, the interest elasticity in the IS curve, $\varphi$, corresponds to the intertemporal elasticity of substitution. The disturbance $g_{t}$ is a function of expected changes in government purchases relative to expected changes in potential output (see footnote 10). Since $g_{t}$ shifts the IS curve, it is interpretable as a demand shock. Finally, adding investment and capital to the model changes the details of equation (2.1). But it does not change the fundamental qualitative aspects: output demand still depends inversely on the real rate and positively on expected future output.

It is instructive to iterate equation (2.1) forward to obtain

\footnotetext{
${ }^{10}$ Using the market clearing condition $Y_{t}=C_{t}+E_{t}$, where $E_{t}$ is government consumption, we can rewrite the log-linearized consumption Euler equation as:

$$
y_{t}-e_{t}=-\varphi\left[i_{t}-E_{t} \pi_{t+1}\right]+E_{t}\left\{y_{t+1}-e_{t+1}\right\}
$$

where $e_{t} \equiv-\log \left(1-\frac{E_{t}}{Y_{t}}\right)$ is taken to evolve exogenously. Using $x_{t} \equiv y_{t}-z_{t}$, it is then possible to derive the demand for output as

$$
x_{t}=-\varphi\left[i_{t}-E_{t} \pi_{t+1}\right]+E_{t} x_{t+1}+g_{t}
$$

where $g_{t}=E_{t}\left\{\Delta z_{t+1}-\Delta e_{t+1}\right\}$.
} 


$$
x_{t}=E_{t} \sum_{i=0}^{\infty}\left\{-\varphi\left[i_{t+i}-\pi_{t+1+i}\right]+g_{t+i}\right\}
$$

Equation (2.5) makes transparent the degree to which beliefs about the future affect current aggregate activity within this framework. The output gap depends not only on the current real rate and the demand shock, but also on the expected future paths of these two variables. To the extent monetary policy has leverage over the short term real rate due to nominal rigidities, equation (2.5) suggests that expected as well as current policy actions affects aggregate demand.

The Phillips curve, (2.2), evolves from staggered nominal price setting, in the spirit of Stanley Fischer (1977) and John Taylor (1980). ${ }^{11}$ A key difference is that the individual firm price setting decision, which provides the basis for the aggregate relation, is derived from an explicit optimization problem. The starting point is an environment with monopolistically competitive firms: When it has the opportunity, each firm chooses its nominal price to maximize profits subject to constraints on the frequency of future price adjustments.

Under the standard scenario, each period the fraction $1 / X$ of firms set prices for $X>1$ periods. In general, however, aggregating the decision rules of firms who are setting prices on a staggered basis is cumbersome. For this reason, underlying the specific derivation of equation (2.2) is an assumption due to Guillermo Calvo (1983) that greatly simplifies the problem: In any given period a firm has a fixed probability $\theta$ it must keep its price fixed during that period and, hence a probability $1-\theta$ that it may adjust. ${ }^{12}$ This probability, further, is independent of

\footnotetext{
${ }^{11}$ See Gali and Gertler (1998) and Sbordone (1998) and for some empirical support for this kind of Phillips curve relation.

${ }^{12}$ The Calvo formulation has become quite common in the literature. Work by Yun (1996),
} 
the time that has elapsed since the last time the firm changed price. Accordingly, the average time over which a price is fixed is $\frac{1}{1-\theta}$. Thus, for example, if $\theta=.75$, prices are fixed on average for a year. The Calvo formulation thus captures the spirit of staggered setting, but facilitates the aggregation by making the timing of a firms' price adjustment independent of its history.

Equation (2.2) is simply a loglinear approximation about the steady state of the aggregation of the individual firm pricing decisions. Since the equation relates the inflation rate to the output gap and expected inflation, it has the flavor of a traditional expectations-augmented Phillips curve (see, e.g., Olivier Blanchard, 1997). A key difference with the standard Phillips curve is that expected future inflation, $E_{t} \pi_{t+1}$, enters additively, as opposed to expected current inflation, $E_{t-1} \pi_{t} \cdot{ }^{13}$ The implications of this distinction are critical: To see, iterate (2.2) forward to obtain

$$
\pi_{t}=E_{t} \sum_{i=0}^{\infty} \beta^{i}\left[\lambda x_{t+i}+u_{t+i}\right]
$$

In contrast to the traditional Phillips curve, there is no arbitrary inertia or lagged dependence in inflation. Rather, inflation depends entirely on current and expected future economic conditions. Roughly speaking, firms set nominal price based on the expectations of future marginal costs. The variable $x_{t+i}$ captures movements in marginal costs associated with variation in excess demand. The shock $u_{t+i}$, which we refer as "cost push", captures anything else that might af-

King and Wolman (1995), Woodford (1996) and others has initiated the revival.

${ }^{13}$ Another key difference is that the explicit derivation restricts the coefficient $\lambda$ on the output gap. In particular, $\lambda$ is decreasing in $\theta$, which measures the degree of price rigidity. Thus, the longer prices are fixed on average, the less sensitive is inflation to movements in the output gap. 
fect expected marginal costs. ${ }^{14}$ We allow for the cost push shock to enable the model to generate variation in inflation that arises independently of movement in excess demand, as appears present in the data (see, e.g., Fuhrer and Moore 1995). To close the model, we take the nominal interest rate as the instrument of monetary policy, as opposed to a money supply aggregate. As Bernanke and Ilian Mihov (1998) show, this assumption provides a reasonable description of Federal Reserve operating procedures since 1965, except for the brief period of non-borrowed reserves targeting (1980-82) under Paul Volcker. ${ }^{15}$ With the nominal rate as the policy instrument, it is not necessary to specify a money market

${ }^{14}$ The relation for inflation that evolves from the Calvo model takes the form

$$
\pi_{t}=\beta E_{t}\left\{\pi_{t+1}\right\}+\delta m c_{t}
$$

where $m c_{t}$ denotes the deviation of (real) marginal cost from its steady state value. To then relate inflation to the output gap, the literature typically makes assumptions on technology, preferences, and the structure of labor markets to justify a proportionate relation between real marginal cost and the output gap, so that $m c_{t}=\kappa x_{t}$ holds, where $\kappa$ is the output elasticity of real marginal cost. In this instance, one can rewrite the relation for inflation in terms of the output gap, as follows: $\pi_{t}=\beta E_{t}\left\{\pi_{t+1}\right\}+\lambda x_{t}$ (see Gali and Gertler (1998) for details). In this context, the disturbance $u_{t}$ in $(2.2)$ is interpretable as reflecting deviations from the condition $m c_{t}=\kappa x_{t}$. (Indeed the evidence in Gali and Gertler (1998) suggests that $m c_{t}$ does not vary proportionately with $x_{t}$ ). Deviatons from this proportionality condition could be caused, for example, by movements in nominal wages that push real wages away from their "equilibrium" values due to frictions in the wage contracting process. On this latter point, see Erceg, Henderson and Levin (1998). Another interpretation of the $u_{t}$ shock (suggested to us by Bob King) is that it could simply reflect some type of systematic pricing error.

${ }^{15}$ Roughly speaking, Bernanke and Mihov (1998) present formal evidence showing that the Federal Reserve intervenes in the market for non-borrowerd bank reserves to support its choice for the level of the Federal Funds rate the overnight market for bank reserves. (Christiano, Eichenbaum, and Evans, 1998, though, take issue with the identifying assumptions in the Bernanke-Mihov test). Informally, Federal Reserve policy actions in recent years routinely take the form of announcing a target for the Federal funds rate (see, e.g, Rudebusch, 1995). Policy discussions, further, focus on whether to adjust that target, and by how much. In this context, the view that the Funds rate is the policy instrument is widely held by both practioners of monetary policy and academic researchers (see, e.g., Goodfriend (1991), Taylor (1993) and Walsh (1998). 
equilibrium condition (i.e., an LM curve). ${ }^{16}$ In section 5, we discuss the implications of using instead a narrow monetary aggregate as the policy instrument.

Though simple, the model has the same qualitative core features as more complex, empirically based frameworks that are used for policy analysis. ${ }^{17}$ As in these applied frameworks, temporary nominal price rigidities play a critical role. With nominal rigidities present, by varying the nominal rate, monetary policy can effectively change the short term real rate. Through this classic mechanism it gains leverage over the near term course of the real economy. In contrast to the traditional mechanism, though, beliefs about how the central bank will set the interest rate in the future also matter, since both households and firms are forward looking. In this kind of environment, how monetary policy should respond in the short run to disturbances that buffet the economy is a nontrivial decision. Resolving this issue is the essence of the contemporary debate over monetary policy.

\subsection{The Policy Objective}

The central bank objective function translates the behavior of the target variables into a welfare measure to guide the policy choice. We assume, following much of the literature, that this objective function is over the target variables $x_{t}$ and $\pi_{t}$, and takes the form:

\footnotetext{
${ }^{16}$ With the interest rate as the policy instrument, the central bank adjusts the money supply to hit the interest rate target. In this instance, the condition that money demand equal money supply simply determines the value of the money supply that meets this criteria.

${ }^{17}$ Some prominent examples include the recently renovated large scale model used by the Federal Reserve Board, the FRB-US model (see Brayton, Levin, Tyron and Williams, 1997), and the medium scale models of Taylor (1979, 1993b) and Fuhrer and Moore (1995a, 1995b).
} 


$$
\max -\frac{1}{2} E_{t}\left\{\sum_{i=0}^{\infty} \beta^{i}\left[\alpha x_{t+i}^{2}+\pi_{t+i}^{2}\right]\right\}
$$

where the parameter $\alpha$ is the relative weight on output deviations. Since $x_{t} \equiv$ $y_{t}-z_{t}$, the loss function takes potential output $z_{t}$ as the target. It also implicitly takes zero as the target inflation, but there is no cost in terms of generality since inflation is expressed as a percent deviation from trend. ${ }^{18}$

While there has been considerable progress in motivating behavioral macroeconomic models from first principles, until very recently, the same has not been true about rationalizing the objectives of policy. Over the past several years, there have been a number of attempts to be completely coherent in formulating the policy problem by taking as the welfare criterion the utility of a representative agent within the model. ${ }^{19}$

One limitation of this approach, however, is that the models that are currently available do not seem to capture what many would argue is a major cost of inflation, the uncertainty that its variability generates for lifetime financial planning and for business planning (see, e.g., Brad DeLong, 1997). ${ }^{20}$ Another issue is that, while the widely used representative agent approach may be a reasonable way to motivate behavioral relationships, it could be highly misleading as a guide to welfare analysis. If some groups suffer more in recessions than others (e.g. steel workers versus professors) and there are incomplete insurance and credit mar-

\footnotetext{
${ }^{18}$ Put differently, under the optimal policy, the target inflation rate pins down the trend inflation rate. The loss function thus penalizes deviations from this trend.

${ }^{19}$ Some examples of this approach include Aiyagari and Braun (1997), King and Wolman (1995), Ireland (1996a), Carlstrom and Fuerst (1995), and Rotemberg and Woodford (1997).

${ }^{20}$ Underlying this kind of cost is the observation that contracts are typically written in nominal terms and, for reasons that are difficult to explain, not perfectly indexed to the price level. On this issue, see the discussion in Shiller (1997) and the associated comment by Hall (1997).
} 
kets, then the utility of a hypothetical representative agent might not provide an accurate barometer of cyclical fluctuations in welfare.

With certain exceptions, much of the literature takes a pragmatic approach to this issue by simply assuming that the objective of monetary policy is to minimize the squared deviations of output and inflation from their respective target levels. However, Julio Rotemberg and Michael Woodford (1998) and Woodford (1998) provide a formal justification for this approach. These authors show that an objective function looking something like equation (2.7) may be obtained as a quadratic approximation of the utility-based welfare function. In this instance, the relative weight $\alpha$, is a function of the primitive parameters of the model.

In what follows we simply adopt the quadratic objective given by (2.7), appealing loosely to the justification offered in Rotemberg and Woodford (1998). Judging by the number of papers written by Federal Reserve economists that follow this lead, this formulation does not seem out of sync with the way monetary policy operates in practice (at least implicitly). ${ }^{21}$ The target level of output is typically taken to be the natural level of output, based on the idea that this is the level of output that would obtain absent any wage and price frictions. Yet, if distortions exist in the economy (e.g., imperfect competition or taxes), a case can be made that the welfare maximizing level of output may exceed its natural level. This issue becomes important in the context of policy credibility, but we defer it for now.

What should be the target rate of inflation is perhaps an even more ephemeral question, as is the issue of what should be the relative weight assigned to output and inflation losses. In the U.S., policy-makers argue that "price stability" should

\footnotetext{
${ }^{21}$ See, for example, Williams (1997) and references therein.
} 
be the ultimate goal. But they define price stability as the inflation rate at which inflation is no longer a public concern. In practice, it is argued that an inflation rate between one and three percent seems to meet this definition (e.g., Bernanke and Mishkin, 1997). A further justification for this criteria is that the official price indices may be overstating the true inflation rate by a percent or two, as argued recently by the Boskin Commission. In this regard, interestingly, the Bundesbank has had for a long time an official inflation target of two percent. ${ }^{22}$ They similarly argue that this positive rate of inflation is consistent with price stability, and cite measurement error as one of the reasons (Clarida and Gertler, 1997).

It is clear that the experience of 1970s awakened policy-makers to the costs of high inflation (DeLong, 1997). Otherwise, there is no directly observable indicator of the relative weights assigned to output and inflation objectives. Nor, argues Blinder (1997), is there any obvious consensus among policy-makers about what these weights really are in practice. It is true that there has been a growing consensus that the primary aim of monetary policy be to control inflation (see, e.g., Bernanke and Mishkin, 1997). But this discussion in many respects is about what kind of policy rule may be best, as opposed to what the underlying welfare function looks like.

For our purposes, however, it is reasonable to take the inflation target and preference parameters as given and simply explore the implications for optimal policy rules.

\footnotetext{
${ }^{22}$ Two percent is also the upper bound of the inflation target range established by the European Central Bank. On the other hand, Feldstein (1997) argues that the tax distortions that arise because corporate and personal income taxes are not indexed to inflation justify moving from three percent to zero inflation.
} 


\subsection{The Policy Problem and Discretion versus Rules}

The policy problem is to choose a time path for the instrument $i_{t}$ to engineer time paths of the target variables $x_{t}$ and $\pi_{t}$ that maximize the objective function (2.7), subject to the constraints on behavior implied by (2.1) and (2.2). This formulation is in many ways in the tradition of the classic Jan Tinbergen (1952)/ Henri Theil (1961) (TT) targets and instruments problem. As with TT, the combination of quadratic loss and linear constraints yields a certainty equivalent decision rule for the path of the instrument. The optimal feedback rule, in general, relates the instrument to the state of the economy.

There is, however, an important difference from the classic problem: The target variables depend not only on the current policy but also on expectations about future policy: The output gap depends on the future path of the interest rate (equation 2.5); and, in turn, inflation depends on the current and expected future behavior of the output gap (equation 2.6). As Finn Kydland and Edward Prescott (1977) originally emphasized, in this kind of environment, credibility of future policy intentions becomes a critical issue. For example, a central bank that can credibly signal its intent to maintain inflation low in the future may be able to reduce current inflation with less cost in terms of output reduction than might otherwise be required ${ }^{23}$. In section 4 , we illustrate this point explicitly.

From the standpoint of policy design, the issue is to identify whether some type

\footnotetext{
${ }^{23}$ In this regard, we stress further that, in contrast to conventional wisdom, the issue of credibility in monetary policy is not tied to central bank objectives over output. In the classic, Barro/Gordon (1983) formulation (and countless papers thereafter), the central bank's desire to push output above potential output above gives rise to the credibility problem. However, as we make clear in section 4, gains from commitment potentially emerge whenever private sector behavior depends on beliefs about future, even if central bank objectives over output are perfectly aligned.
} 
of credibility-enhancing commitment may be desirable. Answering this question boils down to comparing optimal policy under discretion versus rules (using the terminology of the literature). In our context, a central bank operating under discretion chooses the current interest rate by reoptimizing every period. Any promises made in the past do not constrain current policy. Under a rule, it chooses a plan for the path of the interest rates that it sticks to forever. The plan may call for adjusting the interest rate in response to the state of the economy, but both the nature and size of the response are etched in stone.

Two points need to be emphasized. First, the key distinction between discretion and rules is whether current commitments constrain the future course of policy in any credible way. In each instance, the optimal outcome is a feedback policy that relates the policy instrument to the current state of the economy in a very specific way. The two approaches differ, however, in their implications for the link between policy intentions and private sector beliefs. Under discretion, a perceptive private sector forms its expectations taking into account how the central bank adjusts policy, given that the central bank is free to re-optimize every period. The rational expectations equilibrium thus has the property the central bank has no incentive to change its plans in an unexpected way, even though it has the discretion to do so. (For this reason, the policy that emerges in equilibrium under discretion is termed "time consistent.") In contrast, under a rule, it is simply the binding commitment that makes the policy believable in equilibrium.

Second, (it should almost go without saying that) the models we use are nowhere near the point where it is possible to obtain a tightly specified policy rule that could be recommended for practical use with great confidence. Nonetheless, it is useful to work through the cases of discretion and rules in order to develop a 
set of normative guidelines for policy behavior. As Taylor (1993a) argues, common sense application of these guidelines may improve the performance of monetary policy. We expand on this point later. In addition, understanding the qualitative differences between outcomes under discretion versus rules can provide lessons for the institutional design of monetary policy. For example, as we discuss, Rogoff's (1985) insightful analysis of the benefits of a conservative central bank chairman is a product of this type of analysis. Finally, simply understanding the qualitative aspects of optimal policy management under discretion can provide useful normative insights, as we show shortly.

We proceed in the next section to derive the optimal policy under discretion. In a subsequent section we then evaluate the implications of commitment.

\section{Optimal Monetary Policy without Commitment}

We begin with the case without commitment ("discretion") for two reasons. First, at a basic level this scenario accords best with reality. In practice, no major central bank makes any kind of binding commitment over the course of its future monetary policy. In this respect, it seems paramount to understand the nature of optimal policy in this environment. Second, as we have just discussed, to fully comprehend the possible gains from commitment to a policy rule and other institutional devices that might enhance credibility, it is necessary to understand what the benchmark case of discretion yields.

Under discretion, each period the central bank chooses the triplet $\left\{x_{t}, \pi_{t}, i_{t}\right\}$, consisting of the two target variables and the policy instrument, to maximize the objective (2.7) subject to the aggregate supply curve (2.2) and the IS curve, (2.1). 
It is convenient to divide problem into two stages: First, the central bank chooses $x_{t}$ and $\pi_{t}$ to maximize the objective (2.7), given the inflation equation $(2.2){ }^{24}$ Then, conditional on the optimal values of $x_{t}$ and $\pi_{t}$, it determines the value of $i_{t}$ implied by the IS curve (2.1) (i.e., the interest rate that will support $x_{t}$ and $\pi_{t}$ ).

Since it cannot credibly manipulate beliefs in the absence of commitment, the central bank takes private sector expectations as given in solving the optimization problem. ${ }^{25}$ (Then, conditional on the central bank's optimal rule, the private sector forms beliefs rationally.) Because there are no endogenous state variables, the first stage of the policy problem reduces to the following sequence of static optimization problems: ${ }^{26}$ Each period, choose $x_{t}$ and $\pi_{t}$ to maximize

$$
-\frac{1}{2}\left[\alpha x_{t}^{2}+\pi_{t}^{2}\right]+F_{t}
$$

subject to

$$
\pi_{t}=\lambda x_{t}+f_{t}
$$

\footnotetext{
${ }^{24}$ Since all the qualitative results we derive stem mainly from the first stage problen, what is critical is the nature of the short run Phillips curve. For our baseline analysis, we use the Phillipscurve implied the New Keynesian model. In section 6 we consider a very general Phillips curve that is a hybrid of different approaches and show that the qualitative results remain intact. It is in this sense that our analysis is quite robust.

${ }^{25}$ We are ignoring the possibility of reputational equilibria that could support a more efficient outcome. That is, in the language of game theory, we restrict attention to Markov perfect equilibria. One issue that arises with reputational equilibria is that there are multiplicity of possible equilibria. Rogoff (1987) argues that the fragility of the resulting equilibria is an unsatisfactory feature of this approach. See also, Ireland (1996b). On the other hand, Chari, Christiano and Eichenbaum (1998) argue that this indeterminacy could provide a source of business fluctuations.

${ }^{26}$ In section 6 , we solve for the optimum under discretion for the case where an endogenous state variable is present. Within the Markov perfect equilibrium, the central bank takes private sector beliefs as a given function of the endogenous state.
} 
taking as given $F_{t}$ and $f_{t}$, where $F_{t} \equiv-\frac{1}{2} E_{t}\left\{\sum_{i=1}^{\infty} \beta^{i}\left[\alpha x_{t+i}^{2}+\pi_{t+i}^{2}\right]\right\}$ and $f_{t} \equiv$ $\beta E_{t} \pi_{t+1}+u_{t}$. Equations (3.1) and (3.2) simply reformulate (2.7) and (2.2) in a way that makes transparent that, under discretion, (a) future inflation and output are not affected by today's actions, and (b) the central bank cannot directly manipulate expectations.

The solution to the first stage problem yields the following optimality condition:

$$
x_{t}=-\frac{\lambda}{\alpha} \pi_{t}
$$

This condition implies simply that the central bank pursue a "lean against the wind" policy: Whenever inflation is above target, contract demand below capacity (by raising the interest rate); and vice-versa when it is below target. How aggressively the central bank should reduce $x_{t}$ depends positively on the gain in reduced inflation per unit of output loss, $\lambda$, and inversely on the relative weight placed on output losses, $\alpha$.

To obtain reduced form expressions for $x_{t}$ and $\pi_{t}$, combine the optimality condition (3.3) with the aggregate supply curve (2.2), and then impose that private sector expectations are rational:

$$
\begin{gathered}
x_{t}=-\lambda q u_{t} \\
\pi_{t}=\alpha q u_{t}
\end{gathered}
$$

where 


$$
q=\frac{1}{\lambda^{2}+\alpha(1-\beta \rho)}
$$

The optimal feedback policy for the interest rate is then found by simply inserting the desired value of $x_{t}$ in the IS curve (2.1):

$$
i_{t}=\gamma_{\pi} E_{t} \pi_{t+1}+\frac{1}{\varphi} g_{t}
$$

where

$$
\begin{aligned}
& \gamma_{\pi}=1+\frac{(1-\rho) \lambda}{\rho \varphi \alpha}>1 \\
& E_{t} \pi_{t+1}=\rho \pi_{t}=\rho \alpha q u_{t}
\end{aligned}
$$

This completes the formal description of the optimal policy.

From this relatively parsimonious set of expressions there emerge a number of key results that are reasonably robust findings of the literature:

Result 1:. To the extent cost push inflation is present, there exists a short run trade-off between inflation and output variability.

This result was originally emphasized by Taylor (1979) and is an important guiding principle in many applied studies of monetary policy that have followed. ${ }^{27}$

\footnotetext{
${ }^{27}$ For some recent examples, see Williams (1997), Fuhrer (1997a) and Orphanides, Small, Wilcox and Wieland (1997). An exception, however, is Jovanovic and Ueda (1997) who demon-
} 
A useful way to illustrate the trade-off implied by the model is to construct the corresponding efficient policy frontier. The device is a locus of points that characterize how the unconditional standard deviations of output and inflation under the optimal policy, $\sigma_{x}$ and $\sigma_{\pi}$, vary with central bank preferences, as defined by $\alpha$. Figure 1 portrays the efficient policy frontier for our baseline model. ${ }^{28}$ In $\left(\sigma_{x}, \sigma_{\pi}\right)$ space the locus is downward sloping and convex to the origin. Points to the right of the frontier are inefficient. Points to the left are infeasible. Along the frontier there is a trade-off: As $\alpha$ rises (indicating relatively greater preference for output stability), the optimal policy engineers a lower standard deviation of output, but at the expense of higher inflation volatility. The limiting cases are instructive:

$$
\begin{gathered}
\text { As } \alpha \rightarrow 0: \quad \sigma_{x}=\frac{\sigma_{u}}{\lambda} ; \quad \sigma_{\pi}=0 \\
\text { As } \alpha \rightarrow \infty: \quad \sigma_{x}=0 ; \quad \sigma_{\pi}=\frac{\sigma_{u}}{1-\beta \rho}
\end{gathered}
$$

where $\sigma_{u}$ is the standard deviation of the cost push innovation.

It is important to emphasize that the trade-off emerges only if cost push inflation is present. In the absence of cost inflation (i.e., with $\sigma_{u}=0$ ), there is no trade-off.. In this instance, inflation depends only on current and future demand. By adjusting interest rates to set $x_{t}=0, \forall t$, the central bank is able to hit its inflation and output targets simultaneously, all the time. If cost push factors drive inflation, however, it is only possible to reduce inflation in the near term by

strate that in an environment of incomplete contracting, increased dispersion of prices may reduce output. Stabilizing prices in this environment then raises output.

${ }^{28}$ Equations (3.4) and (3.5) define the frontier for the baseline model. 
contracting demand. This consideration leads to the next result:

Result 2: The optimal policy incorporates inflation targeting in the sense that it requires to aim for convergence of inflation to its target over time. Extreme inflation targeting, however, i.e., adjusting policy to immediately reach an inflation target is optimal under only one of two circumstances: (1) cost push inflation is absent; or (2) there is no concern for output deviations (i.e., $\alpha=0$ ).

In the general case, with $\alpha>0$ and $\sigma_{u}>0$, there is gradual convergence of inflation back to target. From equations (3.5) and (2.4), under the optimal policy

$$
\lim _{i \rightarrow \infty} E_{t}\left\{\pi_{t+i}\right\}=\lim _{i \rightarrow \infty} \alpha q \rho^{i} u_{t}=0
$$

In this formal sense, the optimal policy embeds inflation targeting. ${ }^{29}$ With exogenous cost push inflation, policy affects the gap between inflation and its target along the convergent path, but not the rate of convergence. In contrast, in the presence of endogenous inflation persistence, policy will generally affect the rate of convergence as well, as we discuss later.

The conditions for extreme inflation targeting can be seen immediately from inspection of equations (3.7) and (3.8). When $\sigma_{u}=0$ (no cost push inflation), adjusting policy to immediately hit the inflation target is optimal, regardless of preferences. Since there is no trade-off in this case, it is never costly to try to minimize inflation variability. Inflation being the only concern of policy provides the other rationale for extreme inflation targeting. As equation (3.7) indicates, it

\footnotetext{
${ }^{29}$ Note here that our definition is somewhat different from Svensson (1997a), who defines inflation targeting in terms of the weights on the objective function, i.e., he defines the case with $\alpha=0$ as corresponding to strict inflaiton targeting and $\alpha>0$ as corresponding to flexible inflaton targeting.
} 
is optimal to minimize inflation variance if $\alpha=0$, even with cost push inflation present.

Result 2 illustrates why some conflicting views about the optimal transition path to the inflation target have emerged in the literature. Marvin Goodfriend and Robert King (1997), for example, argue in favor of extreme inflation targeting. Svensson (1997a, 1997b) and Laurence Ball (1997) suggest that, in general, gradual convergence of inflation is optimal. The difference stems from the treatment of cost push inflation: It is absent in the Goodfriend-King paradigm, but very much a factor in the Svensson and Ball frameworks.

Results 1 and 2 pertain to the behavior of the target variables. We now state several results regarding the behavior of the policy instrument, $i_{t}$.

Result 3: Under the optimal policy, in response to a rise in expected inflation, nominal rates should rise sufficiently to increase real rates. Put differently, in the optimal rule for the nominal rate, the coefficient on expected inflation should exceed unity.

Result 3 is transparent from equation (3.6). It simply reflects the implicit targeting feature of optimal policy described in Result 2. Whenever inflation is above target, the optimal policy requires raising real rates to contract demand. Though this principle may seem obvious, it provides a very simple criteria for evaluating monetary policy. For example, Clarida, Gertler and Gali (1997) find that U.S. monetary policy in the pre-Volcker era of 1960-1979 violated this strategy. Federal Reserve policy tended to accommodate rather than fight increases in expected inflation. Nominal rates adjusted, but not sufficiently to raise real rates. The persistent high inflation during this era may have been the end product of the failure to raise real rates under these circumstances. Since 1979, however, the 
Federal Reserve appears to have adopted the kind of implicit inflation targeting strategy that equation (3.6) suggests. Over this period, the Fed has systematically raised real rates in response to anticipated increases in inflationary expectations. We return to this issue later.

Result 4: The optimal policy calls for adjusting the interest rate to perfectly offset demand shocks, $g_{t}$, but perfectly accommodate shocks to potential output, $z_{t}$, by keeping the nominal rate constant.

That policy should offset demand shocks is transparent from the policy rule (3.6). Here the simple idea is that countering demand shocks pushes both output and inflation in the right direction. Demand shocks do not force a short run trade-off between output and inflation.

Shocks to potential output also do not force a short run trade-off.. But they require a quite different policy response. Thus, e.g., a permanent rise in productivity raises potential output, but it also raises output demand in a perfectly offsetting manner, due to the impact on permanent income. ${ }^{30}$ As a consequence the output gap does not change. In turn, there is no change in inflation. Thus, there is no reason to raise interest rates, despite the rise in output. ${ }^{31}$ Indeed, this kind of scenario seems to describe well the current behavior of monetary policy. Output growth was substantially above trend in recent times, but with

\footnotetext{
${ }^{30}$ In this experiment we are holding constant the IS shock $g_{t}$. Since $g_{t}=\left[\left(e_{t}-z_{t}\right)-E_{t}\left(e_{t+1}-\right.\right.$ $\left.z_{t+1}\right)$ ], (see footnote 9), this boils down to assuming either that the shock to $z_{t}$ is permanent (so that $E_{t} z_{t+1}-z_{t}=0$ ) or that $e_{t}$ adjusts in a way to offset movements in $g_{t}$.

${ }^{31}$ That monetary policy should accommodate movements in potential GDP is a theme of the recent literature (e.g., Aiyagari and Braun, 1997, Carlstrom and Fuerst, 1995, Ireland, 1996a and Rotemberg and Woodford, 1997). This view was also stressed in much earlier literature. See Friedman and Kuttner (1996) for a review.
} 
no apparent accompanying inflation. ${ }^{32}$ Based on the view that the rise in output may mainly reflect productivity movements, the Federal Reserve has resisted large interest rate increases.

The central message of Result 4 is that an important task of monetary policy is to distinguish the sources of business cycle shocks. In the simple environment here with perfect observability, this task is easy. Later we explore some implications of relaxing this assumption.

\section{Credibility and the Gains from Commitment}

Since the pioneering work of Kydland and Prescott (1977), Robert Barro and David Gordon (1983), and Rogoff (1985), a voluminous literature has developed on the issue of credibility of monetary policy. ${ }^{33}$ From the standpoint of obtaining practical insights for policy, we find it useful to divide the papers into two strands. The first follows directly from the seminal papers and has received by far the most attention in academic circles. It emphasizes the problem of persistent inflationary bias under discretion. ${ }^{34}$ The ultimate source of this inflationary bias is a central bank that desires to push output above its natural level. The second is emphasized more in applied discussions of policy. It focuses on the idea that disinflating an economy may be more painful than necessary, if monetary policy is perceived as not devoted to fighting inflation. Here the source of the problem is simply that

\footnotetext{
${ }^{32}$ See Lown and Rich (1997) for a discussion of the recent "inflation puzzle."

${ }^{33}$ For recent surveys of the literature, see Fischer (1995), McCallum (1997) and Persson and Tabellini (1997).

${ }^{34}$ While the inflationary bias result is best known example, there may also be other costs of discretion. Svennson (1997c), for example, argues also that discretion may lead to too much inflation variability and too little output variability.
} 
wage and price setting today may depend upon beliefs about where prices are headed in the future, which in turn depends on the course of monetary policy.

These two issues are similar in a sense: They both suggest that a central bank that can establish credibility one way or another may be able to reduce inflation at lower cost. But the source of the problem in each case is different in subtle but important ways. As a consequence the potential empirical relevance may differ, as we discuss below.

We first use our model to exposit the famous inflationary bias result. We then illustrate formally how credibility can reduce the cost of maintaining low inflation, and also discuss mechanisms in the literature that have been suggested to inject this credibility. An important result we wish to stress - and one that we don't think is widely understood in the literature - is that gains from credibility emerge even when central bank is not trying to push output above its natural level. ${ }^{35}$ That is, as long as price setting depends on expectations of the future, as in our baseline model, there may be gains from establishing some form of credibility to curtail inflation. Further, under certain plausible restrictions on the form of the feedback rule, the optimal policy under commitment differs from that under discretion in a very simple and intuitive way. In this case, the solution with commitment resembles that obtained under discretion using a higher effective cost applied to inflation than the social welfare function suggests. ${ }^{36}$ In this respect, we

\footnotetext{
${ }^{35} \mathrm{~A}$ number of papers have shown that a disinflation will be less painful if the private sector perceives that the central bank will carry it out. But they do not show formally that, under discretion, the central bank will be less inclined to do so (see., e.g. Ball, 1995, and Bonfim and Rudebusch, 1997).

${ }^{36}$ With inflationary bias present, it is also possible to improve welfare by assigning a higher cost to inflation, as Rogoff (1985) originally emphasized. But it is not always possible to obtain the optimum under commitment. The point we emphasize is that with inflationary bias absent, it is possible to replicate the solution under commitment (for a restricted family of policy rules)
} 
think, the credibility literature may have some broad practical insights to offer.

\subsection{The Classic Inflationary Bias Problem}

As in Kydland and Prescott (1979), Barro and Gordon (1983), and many other papers, we consider the possibility that the target for the output gap may be $k>0$, as opposed to 0 . The policy objective function is then given by

$$
\max -\frac{1}{2} E_{t}\left\{\sum_{i=o}^{\infty} \beta^{i}\left[\alpha\left(x_{t+i}-k\right)^{2}+\pi_{t+i}^{2}\right]\right\}
$$

The rationale for having the socially optimal level of output exceed its natural level may be the presence of distortions such as imperfect competition or taxes. For convenience, we also assume that price setters do not discount the future, which permits us to fix the parameter $\beta$ in the Phillips curve at unity. ${ }^{37}$

In this case, the optimality condition that links the target variables is given by:

$$
x_{t}^{k}=-\frac{\lambda}{\alpha} \pi_{t}^{k}+k
$$

The superscript $k$ indicates the variable is the solution under discretion for the case $k>0$. Plugging this condition into the IS and Phillips curves, (2.1) and (2.2), yields:

$$
x_{t}^{k}=x_{t}
$$

using the algorithm to solve for the optimum under discretion with an appropriately chosen relative cost of inflation. We elaborate on these issues later in the text.

${ }^{37}$ Otherwise, the discounting of the future by price-setters introduces a long run trade off between inflation and output. Under reasonable parameter values this tradeoff is small and

its presence merely serves to complicate the algebra. See Goodfriend and King (1997) for a discussion. 


$$
\pi_{t}^{k}=\pi_{t}+\frac{\alpha}{\lambda} k
$$

where $x_{t}$ and $\pi_{t}$ are the equilibrium values of the target variables for the baseline case with $k=0$ (see equations (3.4) and (3.5))

Note that output is no different from the baseline case, but that inflation is systematically higher, by the factor $\frac{\alpha}{\lambda} k$. Thus, we have the familiar result in the literature:

Result 5. If the central bank desires to push output above potential (i.e., $k>0$ ), then under discretion a suboptimal equilibrium may emerge with inflation persistently above target, and no gain in output.

The model we use to illustrate this result differs from the simple expectational Phillips curve framework in which it has been typically studied. But the intuition remains the same. In this instance, the central bank has the incentive to announce that it will be tough in the future to lower current inflation (since in this case, current inflation depends on expected future inflation), but then expand current demand to push output above potential. The presence of $k$ in the optimality condition (4.2) reflects this temptation. A rational private sector, however, recognizes the central bank's incentive. In mechanical terms, it makes use of equation (4.2) to forecast inflation, since this condition reflects the central bank's true intentions. Put simply, equilibrium inflation rises to the point where the central bank no longer is tempted to expand output. Because there is no long run trade-off between inflation and output (i.e., $x_{t}$ converges to zero in the long run, regardless of the level of inflation), long run equilibrium inflation is forced systematically above target. 
The analysis has both important positive and normative implications. On the positive side, the theory provides an explanation for why inflation may remain persistently high, as was the case from late 1960s through the early 1980s. Indeed, its ability to provide a qualitative account of this inflationary era is a major reason for its popularity.

The widely stressed normative implication of this analysis is that there may be gains from making binding commitments over the course of monetary policy or, alternatively, making institutional adjustments that accomplish the same purpose. A clear example from the analysis is that welfare would improve if the central bank could simply commit to acting as if $k$ were zero. There would be no change in the path of output, but inflation would decline.

Imposing binding commitments in a model, however, is much easier than doing so in reality. The issue then becomes whether there may be some simple institutional mechanisms that can approximate the effect of the idealized policy commitment. Perhaps the most useful answer to the question comes from Rogoff (1985), who proposed simply the appointment of a "conservative" central banker, taken in this context to mean someone with a greater distaste for inflation (a lower $\alpha$ ), than society as whole:

Result 6: Appointing a central bank chairman who assigns a higher relative cost to inflation than society as a whole, reduces the inefficient inflationary bias that is obtained under discretion when $k>0$.

One can see plainly from equation (4.4) that letting someone with preferences given by $\alpha^{R}<\alpha$ run the central bank will reduce the inflationary bias. ${ }^{38}$ The

\footnotetext{
${ }^{38}$ See Svensson (1997) and Walsh (1998) for a description of how incentive contracts for central
} 
Rogoff solution, however, is not a panacea. We know from the earlier analysis that emphasizing greater reduction in inflation variance may come at the cost of increased output variance. Appointing an extremist to the job (someone with $\alpha$ at or near zero) could wind up reducing overall welfare.

How important the inflationary bias problem emphasized in this literature is in practice, however, is a matter of controversy. Benjamin Friedman and Kenneth Kuttner (1996) point out that inflation in the major OECD countries now appears well under control, despite the absence of any obvious institutional changes that this literature argues is needed to enhance credibility. If this theory is robust, they argue, it should account not only for the high inflation of the sixties and seventies, but also for the transition to an era of low inflation during the 1980s and 1990s. A possible counterargument is that in fact a number of countries, including the U.S., effectively adopted the Rogoff solution by appointing central bank chairmen with clear distaste for inflation.

Another strand of criticism focuses on the plausibility of the underlying story that leads to the inflationary bias. A number of prominent authors have argued that, in practice, it is unlikely that $k>0$ will tempt a central bank to cheat. Any rational central bank, they maintain, will recognize the long term costs of misleading the public to pursue short term gains from pushing output above its natural level. Simply this recognition, they argue, is sufficient to constrain its behavior (e.g. McCallum (1997a), Blinder (1997)). Indeed, Blinder argues, based on his own experience on the Federal Reserve Board, that there was no constituency in favor of pursuing output gains above the natural rate. In formal

bankers may reduce the inflation bias. Also, Faust and Svensson (1998) for a recent discussion of reputational mechanisms. 
terms, he maintains that those who run U.S. monetary policy act as if they were instructed to set $k=0$, which eliminates the inflationary bias.

What is perhaps less understood, however, is that there are gains from enhancing credibility even when $k=0$. To the extent that price setting today depends on beliefs about future economic conditions, a monetary authority that is able to signal a clear commitment to controlling inflation may face an improved short run output/inflation trade-off.. Below we illustrate this point. The reason why this is not emphasized in much of the existing literature on this topic is that this work either tends to focus on steady states (as opposed to short run dynamics), or it employs very simple models of price dynamics, where current prices do not depend on beliefs about the future. In our baseline model, however, short run price dynamics depend on expectations of the future as equation (2.2) makes clear. ${ }^{39}$

\subsection{Improving the Short Run Output/Inflation Trade-off: Gains from Commitment with $k=0$.}

We now illustrate that there may be gains from commitment to a policy rule, even with $k=0$. The first stage problem in this case is to choose a state contingent sequence for $x_{t+i}$ and $\pi_{t+i}$ to maximize the objective (2.7) assuming that the inflation equation (2.2) holds in every period $t+i, i \geq 0$. Specifically, the central bank no longer takes private sector expectations as given, recognizing instead that its policy choice effectively determines such expectations.

To illustrate the gains from commitment in a simple way, we first restrict the form of the policy rule to the general form that arises in equilibrium under discretion, and solve for the optimum within this class of rules. We then show that,

\footnotetext{
${ }^{39}$ This section is based on Galí and Gertler (1999).
} 
with commitment, another rule within this class dominates the optimum under discretion. Hence this approach provides a simple way to illustrate the gains from commitment. Another positive by-product is that the restricted optimal rule we derive is simple to interpret and implement, yet still yields gains relative to the case of discretion. Because the policy is not a global optimum, however, we conclude the section by solving for the unrestricted optimal rule.

\subsubsection{Monetary Policy Under Commitment: The Optimum within a Simple Family of Policy Rules (that includes the optimal rule under discretion)}

In the equilibrium without commitment, it is optimal for the central bank to adjust $x_{t}$ solely in response to the exogenous cost push shock, $u_{t}$. We accordingly consider a rule for the target variable $x_{t}$ that is contingent on the fundamental shock $u_{t}$, in the following way:

$$
x_{t}^{c}=-\omega u_{t}
$$

for all $t$, where $\omega>0$ is the coefficient of the feedback rule, and where $x_{t}^{c}$ denotes the value of $x_{t}$ conditional on commitment to the policy. ${ }^{40}$ Note that the rule includes the optimum under discretion as a special case (i.e., the case with $\omega=\lambda q$ shown in (3.4)).

Combining equations (4.5) with the Phillips curve (2.2), in turn, implies that inflation under the rule, $\pi_{t}^{c}$, is also a linear function of the cost push shock:

\footnotetext{
${ }^{40}$ The policy rule only depends on $u_{t}$ because the central bank can adjust $i_{t}$ to offset any impact of movements in $g_{t}$ on aggregate demand. See equation (4.16).
} 


$$
\begin{aligned}
\pi_{t}^{c} & =\lambda x_{t}^{c}+\beta E_{t} \pi_{t+1}^{c} \\
& =E_{t} \sum_{i=0}^{\infty} \beta^{i}\left[\lambda x_{t+i}^{c}+u_{t+i}\right] \\
& =E_{t} \sum_{i=0}^{\infty} \beta^{i}\left[-\lambda \omega u_{t+i}+u_{t+i}\right] \\
& =\frac{1-\lambda \omega}{1-\beta \rho} u_{t}
\end{aligned}
$$

The problem for the central bank is to choose the optimal value of the feedback parameter $\omega$. Relative to the case of discretion, the ability to commit to a feedback policy provides the central bank with an improved short run output/inflation trade-off.. To this end, note that it is possible to express equation (4.9) as

$$
\pi_{t}^{c}=\frac{\lambda}{1-\beta \rho} x_{t}^{c}+\frac{1}{1-\beta \rho} u_{t}
$$

In this case, a one percent contraction in $x_{t}^{c}$ reduces $\pi_{t}^{c}$ by the factor $\frac{\lambda}{1-\beta \rho}$. Under discretion, reducing $x_{t}$ by one percent only produces a fall in $\pi_{t}$ of $\lambda<\frac{\lambda}{1-\beta \rho}$. The extra kick in the case with commitment is due to the impact of the policy rule on expectations of the future course of the output gap. In particular, the choice of $\omega$ affects not only $x_{t}$ but also beliefs about the course of $x_{t+i}^{c}, i=1,2, \ldots$, since $E_{t} x_{t+i}^{c}=-\omega u_{t}$. A central bank that commits to a tough policy rule (high $\omega$ ), for example, is able to credibly signal that it will sustain over time an aggressive response to a persistent supply shock. Since inflation depends on the future course of excess demand, commitment to the tough policy rule leads to a magnified drop in inflation per unit of output loss, relative to the case of discretion.

To find the optimal value of $\omega$, note first that since $x_{t+i}^{c}$ and $\pi_{t+i}^{c}$ are each a 
constant multiple of the cost push shock $u_{t+i}$, it is possible to express the objective function as a multiple of period $t$ loss:

$$
\begin{aligned}
& \max -\frac{1}{2} E_{t}\left\{\sum_{i=0}^{\infty} \beta^{i}\left[\alpha\left(x_{t+i}^{c}\right)^{2}+\left(\pi_{t+i}^{c}\right)^{2}\right]\right\} \\
\longleftrightarrow & \max -\frac{1}{2}\left[\alpha\left(x_{t}^{c}\right)^{2}+\left(\pi_{t}^{c}\right)^{2}\right] L_{t}
\end{aligned}
$$

with $L_{t} \equiv E_{t}\left\{\sum_{i=0}^{\infty} \beta^{i}\left(u_{t+i} / u_{t}\right)^{2}\right\}>0$. The problem then is to choose $\omega$ to maximize (4.11), subject to (4.10). In this instance, the optimality condition is given by:

$$
x_{t}^{c}=-\frac{\lambda}{\alpha^{c}} \pi_{t}^{c}
$$

where

$$
\alpha^{c} \equiv \alpha(1-\beta \rho)<\alpha
$$

Since $\alpha^{c}<\alpha$, relative to the case of discretion, commitment to the rule implies that it is optimal for the central bank to a engineer a greater contraction in output in response to inflationary pressures. Intuitively, the more aggressive response to inflation is the product of the improved output/inflation trade-off that commitment affords. Specifically, the output cost of lowering inflation declines from $\alpha$ to $\alpha^{c}$ per unit, since reducing inflation a given amount requires, ceteris paribus, only a fraction $(1-\beta \rho)$ of the output loss required under discretion. The decline in the effective cost of reducing inflation, in turn, induces the more aggressive policy response to inflation, as comparing equation (4.12) with equation (3.3) makes clear. 
The equilibrium solutions for $x_{t}^{c}$ and $\pi_{t}^{c}$ are easily obtained by combining equations (4.12) and (4.10):

$$
\begin{gathered}
x_{t}^{c}=-\lambda q^{c} u_{t} \\
\pi_{t}^{c}=-\alpha^{c} q^{c} u_{t}
\end{gathered}
$$

with

$$
q^{c}=\frac{1}{\lambda^{2}+\alpha^{c}(1-\beta \rho)}
$$

It is interesting to observe that the solution under commitment in this case perfectly resembles the solution obtained under discretion that arises when $\alpha$ is replaced with $\alpha^{c}<\alpha$ in the objective function. It follows that, conditional on the value of the cost push shock, $u_{t}$, inflation is closer to target and output is further, relative to the outcome under discretion. ${ }^{41}$

It is straightforward to verify that commitment to the policy rule raises welfare. ${ }^{42}$ The tension produced by such gains from commitment, we think, is compelling from an empirical standpoint. Because inflation depends on expected future output gaps, the central bank would like to convince the private sector

\footnotetext{
${ }^{41}$ Importantly, with endogenous inflation persistence, commitment produces a faster transition of inflation to target, as we discuss later

${ }^{42}$ To verify that commitment raises welfare, simply substitute the implied values for $x_{t}$ and $\pi_{t}$ under the optimal rule for each case into the policy objective function. However, it should be obvious that commitment raises welfare, since the optimal rule under discretion falls within the class of rules that we permitted the central bank to choose in the case with commitment: Yet we found that with commitment it is optimal to choose a different parametrization of the rule than arises in the optimum under discretion.
} 
that it will be tough in the future, but at the same time, not have to contract demand much today. As the future comes to pass, the central bank has the incentive to renege on its planned toughness and, instead, promise again to undertake contractionary policy down the road. To see this, suppose that there is a positive cost push shock. If the central bank is free to deviate from the rule, it will always choose the optimal policy under discretion, which calls for a smaller contraction of output, relative to the case of commitment (again, compare (4.12) and (3.3)). A rational private sector will recognize that incentive and, unless the central bank is able to commit credibly, will not expect large contractions in demand in the future either. As a result, the cost push shock generates higher inflation in the absence of commitment. We stress again that, in contrast to the traditional analysis, this gain from commitment is not tied to the desire of the central bank to push output above potential, but to the forward-looking nature of inflation (and, thus, the importance of expectations about future policy) in our baseline model.

From a policy standpoint, Rogoff's rationale for a conservative central banker carries over perfectly to this case. Indeed with omniscience (i.e. exact knowledge of $\alpha^{c}$ and the true model), an appropriately chosen central banker could replicate the outcome under commitment.

We summarize the findings in Result 7:

Result 7: If price-setting depends on expectations of future economic conditions, then a central bank that can credibly commit to a rule faces an improved short run trade-off between inflation and output. This gain from commitment arises even if the central bank does not prefer to have output above potential (i.e., even when $k=0)$. The solution under commitment in this case perfectly resembles the solution that would obtain for a central bank with discretion that assigned 
to inflation a higher cost than the true social cost.

One additional interesting feature of this case with commitment involves the behavior of interest rates. This can be seen formally by simply replacing $\alpha$ with $\alpha^{c}$ in the interest rate rule under discretion (given by equation (3.6) to obtain

$$
i_{t}=\gamma_{\pi}^{c} E_{t} \pi_{t+1}+\frac{1}{\varphi} g_{t}
$$

with

$$
\gamma_{\pi}^{c} \equiv 1+\frac{(1-\rho) \lambda}{\rho \varphi \alpha^{c}}>1+\frac{(1-\rho) \lambda}{\rho \varphi \alpha} \equiv \gamma_{\pi}
$$

In particular, relative to the case of discretion, the central bank increases the nominal interest rate by a larger amount in response to a rise in expected inflation.

\subsubsection{Monetary Policy Under Commitment: The Unconstrained Opti- mum}

We now provide a brief description of the general solution for the optimal policy under commitment. ${ }^{43}$ Because the derivation is more cumbersome than for the restricted case just described, we defer most of the details to an appendix. As with the simple fundamental based policy, however, the general solution exploits the ability that commitment affords to manipulate private sector expectations of the future.

\footnotetext{
${ }^{43}$ We thank Chris Sims and Albert Marcet for calling to our attention that the globally optimal rule under commitment would likely not fall within the restricted family of rules considered in the previous sub-section.
} 
The first stage problem remains to choose a state-contingent sequence for $x_{t+i}$ and $\pi_{t+i}$ to maximize the objective (2.7) given that the aggregate supply curve (2.2) holds in every period $t+i, i \geq 0$. We no longer restrict the choice of $x_{t}$ to depend on the contemporaneous value of the shock (i.e., $u_{t}$ ), but allow instead for rules that are a function of the entire history of shocks. To find the globally optimal solution to the linear quadratic policy problem under commitment, we follow David Currie and Paul Levine (1993) and Woodford (1998), and form the Lagrangian $^{44}$ :

$$
\max -\frac{1}{2} E_{t}\left\{\sum_{i=0}^{\infty} \beta^{i}\left[\alpha x_{t+i}^{2}+\pi_{t+i}^{2}+\phi_{t+i}\left(\pi_{t+i}-\lambda x_{t+i}-\beta \pi_{t+i+1}-u_{t+i}\right)\right]\right\}
$$

where $\frac{1}{2} \phi_{t+i}$ is the (state-contingent) multiplier associated with the constraint at $t+i$.

It is straightforward to show that the first order conditions yield the following optimality conditions

$$
x_{t+i}-x_{t+i-1}=-\frac{\lambda}{\alpha} \pi_{t+i}, \quad \text { for } i=1,2,3, \ldots
$$

and

$$
x_{t}=-\frac{\lambda}{\alpha} \pi_{t}
$$

Recall that under discretion the optimal policy has the central bank adjust the level of the output gap in response to inflation. The optimal policy under

\footnotetext{
${ }^{44}$ See also King and Wolman, who analyze the optimal monetary policy under commitment in a version of Taylor's (1980) staggered contracts model.
} 
commitment requires instead adjusting the change in the output gap in response to inflation. In other words, commitment changes the level rule for $x_{t}$ under discretion into a difference rule for $x_{t}$, as a comparison of equations (3.3) and (4.18) indicate $^{45}$. The one caveat is that in the initial period the policy is implemented (i.e., period $t$ ) the central bank should simply adjust the level of the output gap $x_{t}$ is response to $\pi_{t}$, as if it were following the optimal policy under discretion, but for that period only.

Because $x_{t+i}$ depends in general on $x_{t+i-1}$, the (unconstrained) optimal policy under commitment is in general not simply a function of the contemporaneous state variable $u_{t+i}$. As Woodford (1998) emphasizes in a related context, the lagged dependence in the policy rule arises as a product of the central bank's ability under commitment to directly manipulate private sector expectations. ${ }^{46}$ To see this for our framework, keep in mind that $\pi_{t}$ depends not only on current $x_{t}$ but also on the expected future path of $x_{t+i}$. Then suppose, for example, that there is a cost push shock that raises inflation above target at time $t$. The optimal response under discretion, as we have seen, is to reduce $x_{t}$, but then let $x_{t+i}$ revert back to trend over time as $\pi_{t+i}$ falls back to target. The optimal policy under commitment, however, is to continue to reduce $x_{t+i}$ as long as $\pi_{t+i}$ remains above target. The (credible) threat to continue to contract $x_{t}$ in the future, in turn, has

\footnotetext{
${ }^{45}$ Woodford (1998) makes the connection between the lagged dependence in the optimal rule under commitment and the lagged dependence that appears to arise in interest rate behavior under practice (see section 5.2). Roughly speaking, since the interest rate affects the output gap, lagged dependence in the latter translates into lagged dependence in the former.

${ }^{46}$ Woodford (1998) considers a closely related environment. The difference is that in his framework the policy-maker confronts a tradeoff between inflation and the output gap ultimately because his objective function includes a target for the nominal interest rate (along with targets for the output gap and inflation), whereas in our framework the tradeoff arises due to the cost push shock.
} 
the immediate effect of dampening current inflation (given the dependency of $\pi_{t}$ on future values of $x_{t}$.). Relative to the case of discretion, accordingly, the cost push shock has a smaller impact in current inflation. ${ }^{47}$

As with the constrained policy, the globally optimal policy under commitment exploits the ability of the central bank to influence $\pi_{t}$ with expected future values of $x_{t+i}$ as well as current $x_{t}$. It is also easy to see that, as was the case with the more restrictive rule, the policy is not time consistent. Clearly, if it could reoptimize at $t+i$, the central bank would choose the same policy it implemented at $t$, the one which mimics the rule under discretion for the first period only.

A disadvantage of the unconstrained optimal policy under commitment is that it appears more complex to implement than the constrained one (described by equation 4.12). As we have seen, the constrained rule resembles in every dimension the optimal policy under discretion, but with relatively more weight placed on fighting inflation. Accordingly, as we discussed, it is possible to approximate this policy under discretion with an appropriately chosen central banker. The same is not true, however, for the unconstrained optimal policy. A conservative central banker operating with discretion has no obvious incentive to stick to the difference rule for the output gap implied by equation (4.18).

A further complication, discussed at length in Woodford (1998), is that the interest rate rule that implements the optimal policy might have undesirable side effects. To see this, combine (4.18) and (2.1) to obtain the implied optimal interest rate rule

\footnotetext{
${ }^{47}$ On the surface it appears that the difference rule for $x_{t}$ might be unstable. However, $\pi_{t}$ adjusts to ensure that this is not the case. In particular, the optimal response to a positive cost push shock is to contract $x_{t}$ sufficiently to push $\pi_{t}$ below target. $x_{t}$ then adjusts back up to target over time. The appendix provides the details.
} 


$$
i_{t}=\left(1-\frac{\lambda}{\alpha \varphi}\right) E_{t} \pi_{t+1}+\frac{1}{\varphi} g_{t}
$$

Notice that the coefficient associated with expected inflation is less than one. Under this rule, accordingly, a rise in anticipated inflation leads to a decline in the real interest rate. As we discuss in section 7, if inflationary pressures vary inversely with the real rate, a rule of this type may permit self-fulfilling fluctuations in output and inflation that are clearly suboptimal. ${ }^{48}$

Overall, we have:

Result 8: The globally optimal policy rule under commitment has the central bank partially adjust demand in response to inflationary pressures. The idea is to exploit the dependence of current inflation on expected future demand. In addition, while a appointing conservative central banker may raise welfare under discretion (see Result 7), it does not appear that it is possible to attain the globally optimal rule with this strategy. Finally, there may be some practical complications in implementing the globally optimal interest rate rule that involve potential indeterminacy, as discussed in Woodford (1998).

We conclude that, though substantial progress has been made, our understanding of the full practical implications of commitment for policy-making is still at a relatively primitive stage, with plenty of territory that is worth exploring.

\footnotetext{
${ }^{48}$ Indeterminacy does not arise in the case of discretion and or in the case of the constrained optimum under commitment, since in each instance the implied interest rate rule has an inflation coefficient greater than one. To the extent that such coefficient is not too large, implementation of such a rule will result in a unique equilibrium (see the discussion in section 7 and also in Clarida, Gali and Gertler (1998)).
} 


\section{Practical Complications}

In this section we consider a number of important practical issues that complicate the implementation of monetary policy. While they may not be as exotic as the question of credibility, they are no less important for the day-to-day formulation of policy.

\subsection{Imperfect Information}

Thus far we have assumed that the central bank is able to control perfectly the paths of the key target variables. In practice, of course, this is not the case. One important reason is imperfect observability. At the time it sets interest rates, a central bank may not have all the relevant information available about the state of the economy. Certain data takes time to collect and process. Sampling is imperfect. Even if it has access to data in real time, some key variables such as the natural level of output are not directly observable and are likely measured with great error (see, e.g., the discussion in Arturo Estrella and Mishkin (1998) and Orphanides, (1998)).

Beyond limiting the efficacy of policy, imperfect information has several specific implications. First, it is no longer possible to specify rules simply in terms of target variables. With perfect information, a policy may be expressed equivalently in terms of targets or instruments since a one-to-one relationship generally exists between these variables. With imperfect information, rules for targets can be expressed only in terms of the respective forecasts, as opposed to the ex-post values. An alternative is to use an intermediate target that is directly observable, such as a broad monetary aggregate. 
Second, imperfect information makes the policy instrument choice non-trivial. With perfect information, for example, it does not matter whether the central bank uses the short term interest rate or a monetary aggregate as the policy instrument, so long as the money demand function yields a monotonic relation between the two variables. ${ }^{49}$ With imperfect information, the ex post volatility of a variety of key variables hinges on the instrument choice, as originally argued by William Poole (1970). We illustrate each of these issues below. ${ }^{50}$

\subsubsection{Forecasts as Targets and Intermediate Targets}

We now return to the baseline model with no commitment, and modify it as follows. Suppose that the central bank cannot observe the contemporaneous values of output, inflation, or any of the random shocks. Then let $\Omega_{t}$ be the central bank's information set at the time it fixes the interest rate that prevails at time $t .^{51}$ The optimality condition for policy now is expressed in terms of the expected as opposed to realized target variables.

\footnotetext{
${ }^{49}$ To clarify, a money aggregate can serve as an instrument only if it is directly controllable. A candidate aggregate then would be bank reserves. A broad aggregate such as M3 would not qualify.

${ }^{50}$ For a broad survey of the literature on monetary policy targets and instruments, see Friedman (1991).

${ }^{51}$ Thus, $\Omega_{t}$, is similarly the private sector's information set. Specifically, we let firms observe the current values of their marginal costs, but neither firms nor households can observe contemporaneous aggregate variables. In this instance, the IS and Phillips curve equations are respectively given by

$$
\begin{gathered}
x_{t}=-\varphi\left[\left(i_{t} \mid \Omega_{t}\right)-E_{t-1} \pi_{t+1}\right]+E_{t-1} x_{t+1}+g_{t} \\
\pi_{t}=\lambda x_{t}+\beta E_{t-1} \pi_{t+1}+u_{t}
\end{gathered}
$$
}




$$
E\left\{x_{t} \mid \Omega_{t}\right\}=-\frac{\lambda}{\alpha} E\left\{\pi_{t} \mid \Omega_{t}\right\}
$$

Equation (5.1) is the certainty equivalent version of the condition for the case of perfect information, given by equation (3.3). Certainty equivalence applies here because of the linear quadratic setup (that gives linear decision rules under perfect information) and because the errors in forecasting the target variables are additive.

For ease of exposition, assume that there is no serial correlation in the cost push shock; that is, $\rho=0$, so that $u_{t}=\widehat{u}_{t}$. The implied equilibrium values of the target variables under imperfect information, $x_{t}^{I}$ and $\pi_{t}^{I}$, are given by

$$
\begin{gathered}
x_{t}^{I}=x_{t}+\left(\frac{\lambda}{\lambda^{2}+\alpha} \widehat{u}_{t}+\widehat{g}_{t}\right)=\widehat{g}_{t} \\
\pi_{t}^{I}=\left(1+\frac{\lambda^{2}}{\alpha}\right) \pi_{t}+\lambda \widehat{g}_{t}=\widehat{u}_{t}+\lambda \widehat{g}_{t}
\end{gathered}
$$

where $x_{t}$ and $\pi_{t}$ are the optimal values of the target variables that emerge in case of perfect information (when $u_{t}$ is serially uncorrelated), ${ }^{52}$ and where $\widehat{u}_{t}$ and $\widehat{g}_{t}$ are the unexpected movements in the cost push and demand shocks, respectively. Imperfect information clearly implies greater volatility of inflation, since the central bank cannot immediately act to offset the impact of the shocks. The net effect on the volatility of the output gap is unclear: the inability to offset the demand shock clearly raises output volatility. On the other hand, the central bank cannot offset the inflationary impact of the cost push shock, which works to

\footnotetext{
${ }^{52}$ When $u_{t}$ is serially uncorrelated, $x_{t}=\frac{-\lambda}{\lambda^{2}+\alpha} u_{t}$ and $\pi_{t}=\frac{\alpha}{\lambda^{2}+\alpha} u_{t}$.
} 
reduce the volatility of the output. There is, however, an unambiguous reduction in welfare. ${ }^{53}$

One additional result is worth noting. Since demand shocks now affect the behavior of output, a positive short run co-movement between inflation and output can emerge if $\widehat{g}_{t}$ has a variance sufficiently large relative to that of $\widehat{u}_{t}$.

It is straightforward to generalize the analysis to a setting where the imperfect observability stems from lags in the transmission of monetary policy. This case is of interest since much of the available evidence suggests a lag of six to nine months in the effect of a shift in interest rates on output. ${ }^{54}$ The lag in the effect on inflation is around a year and a half. Suppose, for example, that it takes $j$ periods for a shift in the current interest rate to affect output and another $k$ periods for an impact on inflation. In the left side of equation (5.1) would appear the $j$ period ahead forecast of the output gap, and on the right would be the (suitably discounted) $j+k$ period ahead forecast of inflation.

Svensson (1997a, 1997b) has emphasized the practical importance of this result for the mechanics of inflation targeting (specifically, the kind of inflation targeting that the theory implies (see Result 2 in section 3). A standard criticism of employing an inflation target is that information about the impact of current monetary policy on inflation is only available with a long lag. This information lag, it is argued, makes it impossible to monitor policy performance. It is possible

\footnotetext{
${ }^{53}$ To prove that imperfect information leads to a reduction in welfare, evaluate the welfare function with $x_{t}^{I}$ and $\pi_{t}^{I}$ versus $x_{t}$ and $\pi_{t}$.

${ }^{54}$ Galí (1992), Christiano, Eichenbaum and Evans (1996), and Bernanke and Mihov (1997a) document the slow response of GDP to a policy shock, and the even slower response of prices. Bernanke and Gertler (1995) show that, while the overall response of output is sluggish, certain components of spending do respond quickly, such as housing and consumer durables. Inventories adjust to reconcile the gap between spending and output.
} 
to circumvent this problem, according to Svensson, by focusing instead on the inflation forecast. The forecast is immediately available. It thus provides a quick way to judge the course of policy. A caveat to this argument is that to generate the correct inflation forecast, the central bank must have a good structural model of the economy. ${ }^{55}$ VAR based forecasts are reasonable only if the economy has attained a stationary equilibrium.

A traditional alternative to using the target variable forecasts is to focus on the behavior of a variable that is correlated with the underlying targets but is instead observable and controllable. Broad monetary aggregates are the best known examples of intermediate targets. If demand for a particular aggregate is stable, then this aggregate is likely to have a stable covariance with nominal GDP. In practice, however, experience with monetary targeting has not been successful. The U.S. and the U.K., for example, attempted to regulate the growth of money aggregates in the early 1980s and then quickly abandoned the policy after the aggregates went haywire. ${ }^{56}$ Financial innovation in each instance was the underlying culprit. Even in Germany, long considered a bastion of money targeting, there have been problems. Unstable movements in money demand have forced a retreat from strict money growth targeting. A number of recent papers go further by arguing that in practice Bundesbank policy looks more like inflation targeting (as defined in Result 2) than money targeting (Clarida and

\footnotetext{
${ }^{55}$ Bernanke and Woodford (1997) emphasize the need to make structural forecasts. They also raise some other related criticisms of using forecast-based targets, including the possibility of indeterminacy under this kind of policy rule. We discuss this issue in section 7 .

${ }^{56}$ See Friedman and Kuttner (1996) for a detailed accounting the failure of monetary targeting to take hold in the U.S. See also Estrella and Mishkin (1996). On the other hand, Feldstein and Stock (1997) argue that, with periodic adjustment, a broad monetary aggregate can still be a useful intermediate target.
} 
Gertler (1997), Bernanke and Mihov (1997b)).

For similar reasons, policies that target other kinds of simple indicators, such as commodity prices or long term interest rates have not been widely employed. As Woodford (1994a) has emphasized, the correlation properties of these simple indicators with output and inflation is likely to vary with changes in the policy rule. In the end, there is no simple substitute for employing a structural model.

To summarize, we have

Result 9: With imperfect information, stemming either from data problems or lags in the effect of policy, the optimal policy rules are the certainty equivalent versions of the perfect information case. Policy rules must be expressed in terms of the forecasts of target variables as opposed to the ex post behavior. Using observable intermediate targets, such as broad money aggregates is a possibility, but experience suggests that these indirect indicators are generally too unstable to be used in practice.

\subsubsection{The Instrument Choice Problem: the Interest rate versus a Nar- row Monetary Aggregate}

We now turn to the issue of instrument choice. In practice, the interest rate that major central banks adjust is an overnight rate on interbank lending of funds to meet reserve requirements. ${ }^{57}$ They control this rate by manipulating the supply of bank reserves, i.e., the quantity of high-powered money available for meeting bank reserve requirements. The issue that arises is whether, from an operational

\footnotetext{
${ }^{57}$ See Bernanke and Mihov (1997a) for a discussion of Federal Reserve operating procedures and how they have changed over time.
} 
standpoint, policy should prescribe paths (or rules) for bank reserves or for interest rates.

Suppose that the demand for bank reserves $m_{t}$ is given by ${ }^{58}$

$$
m_{t}-p_{t}=\kappa y_{t}-\eta i_{t}+v_{t}
$$

where $p_{t}$ is the price level and $v_{t}$ is a random disturbance to money demand. If $v_{t}$ is perfectly observable then it does not matter whether $i_{t}$ or $m_{t}$ is employed as the policy instrument. Given the time path of $i_{t}$ implied by the optimal policy, it is possible to back out a time path for $m_{t}$ that supports this policy from equation

Matters change if $v_{t}$ is not observable. With the interest rate as the instrument, the central bank lets the money stock adjust to the money demand shock. There is no impact of money demand shocks on output or inflation because the central bank perfectly accommodates them. With money targeting, the reverse is true: the interest rate and (possibly) output adjust to clear the money market. Assume for simplicity that demand and cost push shocks are absent (i.e., $g_{t}=0, u_{t}=0$ ), so that the only shock is the innovation to money demand. Then the interest rate implied by a money supply instrument $i_{t}^{m}$, is given by

$$
i_{t}^{m}=i_{t}+\frac{1}{\eta+\varphi(\kappa+\lambda)} \widehat{v}_{t}
$$

where $i_{t}$ is the rate that would arise under interest rate targeting and $\widehat{v}_{t}$ is the

\footnotetext{
${ }^{58}$ In the optimizing IS/LM framework of section 2 , it is possible to motivate this specification of the money demand function from first principles, assuming that utility is separable in consumption and real money balances and that consumption is the only type of good (see, e.g., Woodford, 1996).
} 
unexpected movement in money demand.

The key point is that money demand shocks can induce volatile behavior of interest rates. This is particularly true if money demand is relatively interest inelastic in the short run, as is the case for bank reserves. This short run volatility in interest rates will then feed into output volatility, via the aggregate demand relation, equation (2.1). It is for this reason that in practice central banks use interbank lending rates as the policy instrument, an insight due originally to Poole (1970). ${ }^{59}$ Recent empirical work by Bernanke and Mihov (1997a) confirms that except for the brief period non-borrowed reserve targeting under Volcker (1979:10 - 1982:10), the Federal Reserve Board has indeed treated the Funds rate as the policy instrument. In summary, we have

Result 10: Large unobservable shocks to money demand produce high volatility of interest rates when a monetary aggregate is used as the policy instrument. It is largely for this reason that an interest rate instrument may be preferable.

The analysis thus makes clear why the new Federal Reserve Board model does not even bother to include a money aggregate of any form (see Flint Brayton et al. (1997)). Narrow aggregates are not good policy instruments due to the implied interest rate volatility. Broad aggregates are not good intermediate targets because of their unstable relation with aggregate activity.

\footnotetext{
${ }^{59}$ Poole also argued that if unobservable demand shocks were large relative to money demand shocks, then it may be preferable to use a money supply instrument. With a money supply instrument, interest rates will naturally move in an offsetting direction in response to unobserved demand shocks (see Result 4). In practice, the high variablity of money demand shocks seems to dominate the instrument choice, however.
} 


\subsection{Policy Conservatism: Model Uncertainty vs. Exploitation of For- ward Looking Behavior}

In practice, central banks adjust interest rates more cautiously than standard models predict. Put differently, optimal policies derived in a certainty equivalent environment generally predict a much more variable path of interest rates than is observed in practice. An interesting illustration of this point is Rotemberg and Woodford (1997) who estimate a model very similar to our baseline model, and then compute an optimal interest rate policy. The historical interest rate displays much less volatility than the optimal interest rate. This finding is not uncommon. The FRB-US model also generates high interest rate volatility under an optimal rule. Because this degree of volatility seems greater than monetary policy makers seem willing to tolerate in practice, optimal rules are also computed with constraints on the volatility of interest rate changes (see, e.g., John Williams, $(1997)){ }^{60}$

The tendency of the Federal Reserve to adjust rates cautiously is generally referred to as "interest rate smoothing." To be precise, as a number of authors have shown, a monetary policy rule of the following form captures the last twenty or so years of data fairly well:

$$
i_{t}=(1-\rho)\left[\alpha+\beta \pi_{t}+\gamma x_{t}\right]+\rho i_{t-1}+\varepsilon_{t}
$$

where $\alpha$ is a constant interpretable as the steady state nominal interest rate ${ }^{61}$ and

\footnotetext{
${ }^{60} \mathrm{An}$ alternative is to penalize large changes in the nominal interest rate by including the squared deviations of the change in the interest rate $\left(\right.$ i.e, $\left.\left(i_{t}-i_{t-1}\right)^{2}\right)$ in the function, as in Rudebusch and Svensson (1998).

${ }^{61}$ Recall that $\pi_{t}$ represents deviations of inflation from its average (target) level.
} 
where $\rho \in(0,1]$ is a parameter that reflects the degree of lagged dependence in the interest rate. ${ }^{62}$ Interest rate smoothing is present in distinct respects. First, the estimated slope coefficients on inflation and the output gap, $\beta$ and $\gamma$, are typically smaller than what the optimal rule would suggest. Second, there is typically partial adjustment to movements in $\pi_{t}$ and $x_{t}$, reflected by the presence of the lagged interest in the fitted rule. That is, $i_{t}$ is a weighted average of some desired value that depends on the state economy (given by the term $\left[\alpha+\beta \pi_{t}+\gamma x_{t}\right]$ ) and the lagged interest rate, where the relative weights depend on the smoothing parameter $\rho$. Estimates of $\rho$ for quarterly data are typically on the order of 0.8 or 0.9 , which suggests very slow adjustment in practice. The existing theory, by and large, does not readily account for why the central bank should adjust rates in such a sluggish fashion.

Indeed, understanding why central banks choose a smooth path of interest rates than theory would predict is an important unresolved issue. One implication is that the standard certainty equivalence models may not adequately capture the constraints policy-makers face in practice. A natural possibility is that policymakers know far less about the way the world works than is presumed in simple policy experiments.

In general, model uncertainty is a formidable problem. Ideally, one would like to take into account that the central bank is continually learning about the economy as it adjusts its policy. Performing this exercise in a clean way is beyond the frontier of current knowledge. Though, advances in computational methodology have allowed some progress to be made with relatively simple frameworks. ${ }^{63}$

\footnotetext{
${ }^{62}$ See Rudebusch (1995), for example, for a discussion of the persistence in short term interest rates.

${ }^{63}$ Wieland (1997) analyzes policy in a framework where the central bank has to learn the
} 
It is possible to illustrate how model uncertainty could in principle introduce at least some degree of policy caution. Suppose the values of several parameters in the model are random. The central bank knows the distribution of these parameters but not the realization. When it adjusts policy, accordingly, it cannot be sure of the impact on the economy. As originally demonstrated by William Brainard (1969), this kind of uncertainty can introduce caution in policy responses. In contrast to the case of certainty-equivalence, policy-actions now affect the conditional variance of inflation and output, as well as the conditional mean.

To be concrete, suppose that the two parameters of the model, the interest elasticity in the IS equation and the slope coefficient on the output gap are random variables, now given by $\widetilde{\varphi}_{t}=\varphi+\varepsilon_{t}$ and by $\widetilde{\lambda}_{t}=\lambda+\eta_{t} \cdot{ }^{64}$ Assume further that $\varepsilon_{t}$ and $\eta_{t}$ are i.i.d random variables with zero means. The optimality condition for policy then becomes:

$$
E\left\{x_{t} \mid \Omega_{t}\right\}=\frac{\lambda}{\alpha+\lambda^{2} \sigma_{\eta}^{2}} E\left\{\pi_{t} \mid \Omega_{t}\right\}+\left(\alpha+\lambda^{2}\right) \frac{\sigma_{\varepsilon}^{2}}{\varphi} r_{t}
$$

where $r_{t} \equiv i_{t}-E\left\{\pi_{t+1} \mid \Omega_{t}\right\}$ is the ex ante real interest rate. This condition leads to the following result:

Result 11: Parameter uncertainty may reduce the response of the policy instrument to disturbances in the economy. It can thus motivate a smoother path of the interest rate than the certainty equivalent policy implies.

value of the natural rate of unempoyment (which, in our analysis, corresponds to having to learn about potential GDP.)

${ }^{64} \mathrm{We}$ are assuming that the policy-maker knows the first two moments of the random parameters. It may be more plausible to argue that the policy-maker in fact has little idea what the true ditribution looks like. See Onatski and Stock (1999) who analyze the policy problem in this kind of environment using robust control methods. 
Comparing equations (5.1) and (5.7) reveals how parameter uncertainty reduces policy activism. Under certainty equivalence, a rise in inflation above target requires the central bank to raise interest rates to contract demand. ${ }^{65}$ With an uncertain slope coefficient on the output gap in the AS curve, however, contraction of output below potential raises the variability of inflation. This induces the central bank to moderate the contraction in demand, as reflected by the presence of the term $\lambda^{2} \sigma_{\eta}^{2}$ in the coefficient on $E\left\{\pi_{t} \mid \Omega_{t}\right\}$. Similarly, uncertainty about the impact of an increase in the interest rate on the output gap moderates the extent of adjustment in $i_{t}$. The second term on the right side of equation (5.7) captures this latter dampening effect.

This simple form of model uncertainty thus may help explain the relatively low variability of interest rates in the data. One feature of interest rate smoothing it does not appear to capture, however, is the strong lagged dependence in the interest rate. Put differently, the kind of parameter uncertainty we have discussed may explain why the slope coefficients on inflation and the output gap, $\alpha$ and $\beta$, are small relative to the case of certainty equivalence. But it does not explain the partial adjustment, given by the dependence of $i_{t}$ on $i_{t-1} \cdot{ }^{66}$

\footnotetext{
${ }^{65}$ It should also be clear from equation (5.7) that with parameter uncertainty the interest rate no longer adjusts to perfectly offset demand shocks. Suppose, for example, that there is a positive demand shock. The interest rate goes up, but the parameter uncertainty moderates the extent of the rise, relative to the certainty equivalence case.

${ }^{66}$ Sack $(1997 \mathrm{a}, 1997 \mathrm{~b})$ argues, nonetheless, that parameter uncertainty can explain this phenomenon if the uncertainty of the impact of the interest rate on the economy is based on the change in the interest rate $\left(i_{t}-i_{t-1}\right)$ as opposed to the deviation from trend $i_{t}$. In former instance, changes in $i_{t}$ raise the conditional varibiality of output, which induces the central bank to keep $i_{t}$ close to $i_{t-1}$. On the other hand, it is not well understood how the link between model uncertainty and policy conservatism is affected when there is active learning about the economy. Some results suggest that learning should induce active adjustments of the policy instrument to facilitate estimating the true model. See the discussion in Wieland (1997), for example. Also, it is possible to construct examples, where parameter uncertainty leads to increased activism.
} 
Rotemberg and Woodford (1997) offer a novel explanation for the lagged dependence that is based on the leverage that this kind of adjustment rule may provide the central bank over the long term interest rate. The idea is that lagged dependence in $i_{t}$ permits the central bank to manipulate long term rates, and hence aggregate demand, with more modest movements in the short term rate than would be otherwise be required. This kind of rule is thus desirable to the extent the central bank may care about avoiding excessive volatility in the short term interest rate in pursuing its stabilization goals.

To illustrate, consider the special case of equation (5.6) with $\rho=1$. In this instance, the difference in the interest rate $\left(i_{t}-i_{t-1}\right)$, as opposed to the level, is a linear function of $\pi_{t}$ and $x_{t}$. Under the difference rule, the expected future short rate at $t+i, E_{t}\left\{i_{t+i}\right\}$, is given by

$$
\begin{aligned}
E_{t}\left\{i_{t+k}\right\} & =E_{t}\left\{\sum_{j=1}^{k}\left(i_{t+j}-i_{t+j-1}\right)\right\}+i_{t} \\
& =E_{t}\left\{\sum_{j=1}^{k}\left[\alpha+\beta \pi_{t+j}+\gamma x_{t+j}\right]\right\}+i_{t}
\end{aligned}
$$

Assume that the long term rate depends on the sum of expected short rates over the same horizon, in keeping with the expectations hypothesis of the term structure. Then, in comparison with the level rule, the difference rule increases the responsiveness of the long term rate under the feedback policy. Suppose for example that, in reaction to a rise in inflation above target at time $t$, the central bank raises $i_{t}$ above its steady state value. Under the difference rule the increase

See, for example, Sargent (1998). 
in the interest rate has a persistent effect on the path of the expected short rate, since $E_{t}\left\{i_{t+i}\right\}$ depends additively on $i_{t}$. Further, if changes in inflation and output are persistent, then the path of expected short rates will actually be rising, as equation (5.8) makes clear. ${ }^{67}$ The difference rule thus enhances the countercyclical movement of the long rate relative to the movement of short rate. Given that aggregate demand depends on the long rate, this kind of rule thus enables the central bank to stabilize the economy with relatively modest movements in the short rate. ${ }^{68}$

Overall, Rotemberg and Woodford provide a plausible explanation for why central banks may want to introduce lagged dependence in the interest rate. Whether this story can also account for the empirically observed modest response of the short rate to inflation and the output gap (i.e., the low values of $\beta$ and $\gamma$, the slope coefficients on $\pi_{t}$ and $x_{t}$ ) remains to be seen.

Another explanation for policy conservatism and the associated interest rate smoothing includes fear of disrupting financial markets (see, e.g., Goodfriend, (1991)). Sharp unanticipated increases in interest rates can generate capital losses, particularly for commercial banks and other financial institutions that may be exposed to interest rate risk. This consideration might explain why the Federal Reserve chose to raise rates only very gradually during 1994, the tail end of a period of considerable financial distress (see, e.g., the discussion in John Camp-

\footnotetext{
${ }^{67}$ On the surface it appears that the interest rate might explode under the difference rule, since it will continue to increase so long as inflation is above target. However, the rise in the interest rate will dampen demand and inflation. In the context of our model, it does so sufficiently to preclude explosive behavior.

${ }^{68}$ The idea that central bank should pursue a partial adjustment rule to exploit the dependence of demand on future policy is reminiscent of the globally optimal policy under commiment (see section 4.22). Indeed, Woodford (1998) makes this connection formally.
} 
bell, (1995)). Disagreement by policy-makers is another explanation for slow adjustment of rates. Neither of these alternative stories have been well developed, however. In general, understanding why interest rate smoothing occurs in practice is an important unresolved issue.

\subsection{Non-Smooth Preferences and Opportunism}

Another aspect of policy that has received considerable attention involves the process of disinflation. In the baseline model, if inflation is above target, it is always optimal to tighten monetary policy to gradually bring inflation back to the optimum (see Result 2 in Section 3). During his tenure at Federal Reserve Board, however, Blinder proposed the following alternative: If inflation is above but near the optimum, policy should not contract demand. Rather, it should take an "opportunistic" approach. Roughly speaking, being opportunistic boils down to waiting until achieving the inflation target could be done at the least cost in terms of incremental output reduction. Blinder's original concept was vague as to the details. Recent work by researchers at the Federal Reserve Board has filled in a number of the missing pieces.

Athanasios Orphanides and David Wilcox (1996) show that it is possible to rationalize something like opportunistic policy by making a small adjustment of the policy objective function. In particular, suppose that policy-makers care quite a lot about small departures of output from target, at least relative to small departures of inflation. An example of an objective function that capture this phenomenon is given by 


$$
\max -\frac{1}{2} E_{t}\left\{\sum_{i=0}^{\infty} \beta^{i}\left(\alpha\left|x_{t}\right|+\pi_{t+i}^{2}\right)\right\}
$$

With this objective function, the optimality condition for policy becomes:

$$
\begin{aligned}
x_{t} & =0, \text { if }\left|\pi_{t}\right|<\frac{\alpha}{\lambda} \\
\left|\pi_{t}\right| & =\frac{\alpha}{\lambda}, \text { otherwise }
\end{aligned}
$$

Thus, if inflation is within $\frac{\alpha}{\lambda}$ units of the target, the optimal policy is to simply stabilize output. Otherwise, policy should keep inflation at most $\frac{\alpha}{\lambda}$ units from target and then wait for favorable supply shocks that move it closer to target (e.g., favorable movements in the cost push shock $u_{t}$ ). In this respect the policy is opportunistic. A better term for it, however, might be "inflation zone targeting" (Bernanke and Mishkin, 1997). What the policy really amounts to is keeping inflation with a certain range, as opposed to trying to move it to an exact target.

Variations on this theme allow for preferences that generate an inflation zone target, but then has policy trade off between inflation and output goals when inflation is outside the target zone. Orphanides, David Small, Volcker Wieland and Wilcox (1997) (OSWW) provide an example of this more general setup.

It is important to emphasize though, that opportunistic policy behavior that is distinct from the gradualism of the baseline model only arises if cost push factors are present in inflation. This is true because only with cost push inflation present does a trade-off between output and inflation emerge (see Result 1). Indeed, OSWW show that opportunistic policy rules are equivalent to conventional 
gradualist rules in the presence of demand shocks, but differ when there are supply shocks. ${ }^{69}$

In summary, we have

Result 12: If there is more cost associated with small departures of output from target than with small departures of inflation, then an opportunistic approach to disinflation may be optimal. This policy, further, is equivalent to targeting inflation around a zone as opposed to a particular value.

\section{Implications of Endogenous Inflation and Output Persis- tence}

Within our baseline model, the dynamics of output and inflation are due entirely to exogenous force processes. We now consider an alternative framework that allows for endogenous persistence in output and inflation. Our purpose is to show that the results derived in the baseline framework extend to this more general setting. In this regard, we show that our results are not specific to the particular benchmark model we employed, but instead hold across a reasonably broad class of models that are used for applied macroeconomic analysis. The major difference is that with endogenous persistence in inflation, the equilibrium feedback monetary policy now influences the speed of convergence of inflation to its target.

Consider the following generalizations of the IS and aggregate supply curves:

\footnotetext{
${ }^{69}$ For an alternative description of the opportunistic approach, see Bomfin and Rudebusch (1997). These authors emphasize the ratcheting down of inflation and, in particular, explore the role of imperfect credibility.
} 


$$
\begin{gathered}
x_{t}=-\varphi\left[i_{t}-E_{t} \pi_{t+1}\right]+\theta x_{t-1}+(1-\theta) E_{t} x_{t+1}+g_{t} \\
\pi_{t}=\lambda x_{t}+\phi \pi_{t-1}+(1-\phi) \beta E_{t} \pi_{t+1}+u_{t}
\end{gathered}
$$

Equation (6.1) incorporates the lagged output gap in the IS curve. Equation (6.2) adds lagged inflation to the aggregate supply curve. The parameters $\theta$ and $\phi$ index the influence of lagged versus expected future variables. As a result the model nest some important special cases. With $\theta=0$ and $\phi=0$, we recover the baseline model. Conversely, with $\theta=1$ and $\phi=1$, the models becomes (approximately) the backward looking framework that Svensson (1997a, 1997b) and Ball (1997) have used to analyze monetary policy. For simplicity we assume that the disturbances $g_{t}$ and $u_{t}$ are serially uncorrelated (i.e., we set $\mu$ and $\rho$ in equation (2.3) and (2.4) equal to zero.) This simple formulation does not allow for delays in the effect of policy, but we show later that it is easy to amend the analysis to incorporate delayed policy effects.

As we noted earlier, virtually all the major applied macroeconomic models allow for some form of lagged dependence in output and inflation. The primary justification is empirical..$^{70}$ By appealing to some form of adjustment costs, it may be feasible to explicitly motivate the appearance of $x_{t-1}$ within the IS curve. Motivating the appearance of lagged inflation in the aggregate supply curve, however, is a more formidable challenge. ${ }^{71}$ Some frameworks do so by effectively

\footnotetext{
${ }^{70}$ For am empirical justification for including lagged dependent variables, see Fuhrer (1996).

${ }^{71}$ It is possible to motivate a dependency of current inflation on lagged inflation by appealing to adaptive expectations (e.g., suppose $E_{t-1} \pi_{t}=\kappa \pi_{t-1}$.) Indeed, this is the traditional approach (see the discussion in Blanchard, 1997). The issue then becomes motivating the assumption of
} 
appealing to costs of changing the rate of inflation. ${ }^{72}$ This assumption, though, is clearly unattractive. In the spirit of robustness, however, it is important to understand the implications of lagged dependence. This is particularly true given the empirical appeal of this formulation.

We begin with the case of discretion, and then later describe briefly how the results are affected when the central bank can make credible promises. ${ }^{73}$ An analytical solution is not available, except in the polar cases of $\phi=0$ and $\phi=1$. It is, however, possible to provide an intuitive description of the optimum. Let $a_{\pi}$ be a parameter that measures the serial dependence of inflation in the reduced form. Then the optimality condition that governs policy is given by:

$$
\begin{aligned}
x_{t} & =-\frac{\lambda}{\alpha}\left[\pi_{t}+\sum_{k=1}^{\infty} \beta^{k} E_{t} \pi_{t+k}\right] \\
& =-\frac{\lambda}{\alpha\left(1-\beta a_{\pi}\right)} \pi_{t}
\end{aligned}
$$

with

adaptive expectations.

${ }^{72}$ See, for example, Fuhrer and Moore (1995a, 1995b) and Brayton, Levin, Tyron, and Williams (1997)). Gali and Gertler (1998) criticize the existing empirical literature on inflation dynamics, and provide new evidence which suggests that (2.2) is a good first approximation to the data.

${ }^{73}$ As in section 3, we restrict attention to Markov perfect equilibria. In this case, however, we must take into account that inflation is an endogenous state variable. In any stationary equilibrium, therefore, expected inflation will depend on lagged inflation. What the policy maker takes as given, accordingly, is not the level of expected inflation, but rather how private sector expectations of inflation tomorrow respond to movements in inflation today. Simply put, to solve for the equilibrium under discretion, we assume that private sector forecast of $\pi_{t+1}$ takes the form $\nu_{\pi} \pi_{t}+\nu_{u} u_{t}$, where $\nu_{\pi}$ and $\nu_{u}$ are arbitary constants that the policy-maker takes as given. In the rational expectations equilibrium $\nu_{\pi}$ and $\nu_{u}$ equal the true fundamental parameters in the reduced for inflation, $a_{\pi}$ and $a_{u}$. 


$$
\pi_{t}=a_{\pi} \pi_{t-1}+a_{u} u_{t}
$$

and

$$
0 \leq a_{\pi}<1
$$

With inertia present, adjustments in current monetary policy affect future time path of inflation. As consequence, policy now responds not only to current inflation but also to forecasts of inflation into the indefinite future. How much depends positively on $a_{\pi}$, which measures the degree of inflationary persistence.

The coefficients $a_{\pi}$ and $a_{u}$ are functions of the underlying parameters $(\alpha, \lambda, \beta, \phi) .{ }^{74}$ The former, $a_{\pi}$, is key, since it measures the speed of convergence to inflation under the optimal policy. It is possible to show that this parameter lies between zero and unity, implying convergence. The magnitude of $a_{\pi}$ depends positively on the degree of inflation inertia $\phi$. In the baseline case of no inflation inertia, $\phi=0$, implying $a_{\pi}=0 . \quad a_{\pi}$ also depends negatively on the relative cost of inflation, measured by $1 / \alpha$. As in the baseline case, if the distaste for inflation is high ( $\alpha$ is low), the optimal policy aggressively contracts demand whenever inflation is above target: With endogenous persistence, this contraction not only reduces inflation but also increase the speed of convergence to target. Figure 2 illustrates the relation between $a_{\pi}$ and $\alpha$ for three different values of $\phi: \phi=0.01$ (low inertia), $\phi=0.5$ (medium) and $\phi=0.99$ (high).

\footnotetext{
${ }^{74}$ To obtain solutions for $a_{\pi}$ and $a_{u}$, substitute the optimality condition $x_{t}=-\frac{\lambda}{\alpha\left(1-\beta a_{\pi}\right)} \pi_{t}$ and the conjectured solution for $\pi_{t},(6.5)$, into the aggregate supply curve. Then use the methods of undetermined coefficients to solve for $a_{\pi}$ and $a_{u}$. The equation for $a_{\pi}$ is a cubic. The solution is the unique value between zero and unity, which corresponds to the unique stable root.
} 
Combining (6.3) with (6.1) yields the implied optimal interest rate rule:

$$
i_{t}=\gamma_{\pi} E_{t} \pi_{t+1}+\gamma_{x} x_{t-1}+\frac{1}{\varphi} g_{t}
$$

with

$$
\begin{gathered}
\gamma_{\pi}=1+\frac{\lambda\left(1-a_{\pi}\right)}{\varphi \alpha a_{\pi}\left(1-\beta a_{\pi}\right)} \\
\gamma_{x}=\frac{\theta}{\varphi} \\
E_{t} \pi_{t+1}=a_{\pi} \pi_{t}
\end{gathered}
$$

Most of the qualitative results obtained in the baseline case extend to this more general setting. As in the baseline case the policy-maker faces a short run trade-off between output and inflation (Result 1). The effect of inflation inertia is to make this trade off less favorable. Equation (6.3) shows that relative to the baseline case of $\phi=0$, the optimal policy requires a more aggressive response to any burst of inflation. The problem is that any inflation not eliminated today persists into future, potentially requiring more output contraction. Figure 3 illustrates how the trade-off becomes less favorable in this case by plotting the efficient policy frontier for the three benchmark values of $\phi$. In addition, since $0 \leq a_{\pi}<1$, the optimal policy calls for gradual adjustment of inflation to target (Result 2). With $\phi>0$, further, extreme inflation targeting is only optimal if $\alpha=0$, as equation 
(6.3) and Figure 2 suggest.

From the interest rate rule given by equation (6.6) it is apparent that the coefficient on expected inflation exceeds unity, implying that the ex ante real rate must rise in response to higher expected inflation (Result 3). Finally, the interest rate should also adjust to perfectly offset demand shocks, but should not respond to movements in potential output (Result 4.) One interesting difference in this case is that the interest rate responds to the lagged output gap, since this variable now enters the IS curve. Thus, the optimal interest rate rule now resembles the simple gap rules that have been discussed in the literature. We return to this point later. In summary, we have

Result 13: Results 1 through 4 that describe optimal monetary policy under discretion within the baseline model also apply in the case with endogenous output and inflation persistence.

In addition to allowing for lagged dependence in output and inflation, there is also strong empirical justification for incorporating delays in the effect of policy. It is straightforward to extend the analysis to include this real world feature. Suppose, following Svensson (1997a, 1997b) and Ball (1997), that there is a one period delay in the effect of the real interest rate on the output gap and, in turn, a one period delay in the effect of the output gap on inflation. Then the optimality condition becomes, ${ }^{75}$

$$
E_{t}\left\{x_{t+1}\right\}=-\frac{\lambda}{\alpha\left(1-\beta a_{\pi}^{l}\right)} E_{t}\left\{\pi_{t+2}\right\}
$$

\footnotetext{
${ }^{75}$ In this case, the IS curve is given by $x_{t}=-\varphi\left[i_{t-1}-E_{t-1} \pi_{t}\right]+\theta x_{t-1}+(1-\theta) E_{t-1} x_{t+1}+g_{t}$ and the aggregate supply curve is given by $\pi_{t}=\lambda x_{t-1}+\phi \pi_{t-1}+(1-\phi) \beta E_{t} \pi_{t+1}+u_{t}$.
} 
where the parameter $a_{\pi}^{l}$ measures the serial dependence in inflation for this case. It has qualitatively similar properties to $a_{\pi}$ in equation (6.5), with $0 \leq a_{\pi}^{l}<1$. The left side of (6.7) reflects the one period delay in the impact of policy on output and the right side reflects the two period delay on inflation.

Due to the delayed impact of policy, the central bank takes both the output gap at $t, x_{t}$, and the forecast of inflation at $t+1, E_{t}\left\{\pi_{t+1}\right\}$, as predetermined from the vantage of time $t$. The rest of the solution may thus be expressed in terms of these predetermined variables:

$$
\begin{gathered}
E_{t}\left\{\pi_{t+2}\right\}=a_{\pi}^{l} E_{t}\left\{\pi_{t+1}\right\} \\
i_{t}=\gamma_{\pi}^{l} E_{t} \pi_{t+1}+\gamma_{x} x_{t}
\end{gathered}
$$

with

$$
\gamma_{\pi}^{l}=1+\frac{\left(\gamma_{\pi}-1\right) \beta}{a_{\pi}^{l}}>1
$$

The solution closely resembles the case without delay. Any differences just reflect the lagged influence of policy in this environment. The nominal rate still adjusts more than one-for one with expected inflation. Due to the lag structure, though, it adjusts to the current output gap, as opposed to one from the previous period.

We conclude this section with brief discussion of the gains from commitment. It is possible to show that, as in the baseline model, the policy rule under commit- 
ment resembles the rule under discretion that would obtain if the policy-maker assigned a higher relative cost to inflation (lower value of $\alpha$ ) than the true social cost. Because inflation inertia is endogenous in this case, the optimal policy with commitment implies a faster transition of inflation to the optimum relative to what occurs under discretion. This can bee seen by noting that the parameter which governs the speed of convergence of inflation, $a_{\pi}$, is decreasing in the relative cost of inflation $1 / \alpha$ (see Figure 4). ${ }^{76}$. Simply put, disinflations will be swifter than otherwise if credible commitment is possible either directly or indirectly by installing a conservative central bank chairman.

\section{Simple Rules for Monetary Policy}

We next discuss some normative and positive aspects of simple feedback rules for the interest rate that have been discussed in the literature. We then discuss how these instrument-based rules are related to simple rules for targets that have been recently proposed, including inflation targeting and nominal GDP targeting. Finally, we conclude with a brief discussion of the issue of possible indeterminacy of interest rate rules.

\subsection{Simple Interest Rate Rules}

Taylor (1993a) ignited the discussion of simple interest rate rules. ${ }^{77}$ He proposed a feedback policy of the following form:

\footnotetext{
${ }^{76}$ Note that the speed of convergence of inflation is decreasing in $a_{\pi}$.

${ }^{77}$ McCallum (1988) proposed a simple rule for the monetary base. The rule is less popular in policy circles due to the implied interest rate volatility (see Result 9). McCallum (1997) argues, however, that the concern about interest rate volatility is not well understood, a point with which we agree.
} 


$$
i_{t}^{*}=\alpha+\gamma_{\pi}\left(\pi_{t}-\bar{\pi}\right)+\gamma_{x} x_{t}
$$

with

$$
\begin{gathered}
\alpha=\bar{r}+\bar{\pi} \\
\gamma_{\pi}>1, \quad \gamma_{x}>0
\end{gathered}
$$

where $i_{t}^{*}$ is the target interest rate the feedback rule defines, $\bar{\pi}$ is the target inflation rate, and $\bar{r}$ is the long run equilibrium real interest rate. ${ }^{78}$ Also, we now express all variables in levels, as opposed to deviations from trend.

A number of other researchers have considered rules like (7.1) (see, e.g., Henderson and Mckibbon, 1993). Taylor's contribution is to spell out the normative and positive implications. On the normative side, the rule is consistent with the main principles for optimal policy that we have described. It calls for gradual adjustment of inflation to its target (see Result 2). Specifically, it has the nominal rate adjust more than one-for-one with the inflation rate. To the extent lagged inflation is a good predictor of future inflation, the rule thus has real rates adjusting to engineer inflation back to target (see Result 3). Finally, note that the interest rate responds to the output gap as opposed to the level of output. Thus, in at least an approximate sense, the rule calls for a countercyclical response to demand shocks and accommodation of shocks to potential GDP that do not affect

\footnotetext{
${ }^{78}$ The inflation rate Taylor uses is actually the rate over the previous year (as opposed to the previous quarter.)
} 
the output gap (see Result 4).

On the positive side, Taylor showed that with certain parameter values, the rule provides a reasonably good description of policy over the period 1987-1992. These are: $\gamma_{\pi}=1.5, \gamma_{x}=0.5, \bar{\pi}=2$, and $\bar{r}=2$. Taylor used informal judgement to pick them. An interesting question is whether a formal methodology would yield something different.

In this spirit, Clarida, Gertler and Gali (1997a) estimate a simple rule for U.S. monetary policy, and consider how this rule has evolved over time. The specific formulation is a "forward looking" version of the simple Taylor rule:

$$
i_{t}^{*}=\alpha+\gamma_{\pi}\left(E_{t} \pi_{t+1}-\bar{\pi}\right)+\gamma_{x} x_{t}
$$

Under this rule, policy responds to expected inflation as opposed to lagged inflation. In this respect, the formulation is consistent with the optimal rules derived for both the baseline and hybrid models (see equations (3.6) and (6.6)). Another virtue is that this formulation nests the simple Taylor rule as a special case. If either inflation or a linear combination of lagged inflation and the output gap is a sufficient statistic for future inflation, then the specification collapses to the Taylor rule.

Because of the Federal Reserve's tendency to smooth interest rate adjustments (see the discussion in section 5), a static relation like equation (7.2) cannot capture the serial correlation present in the data. We thus allow for the possibility of partial adjustment to the target rate, according to:

$$
i_{t}=\rho i_{t-1}+(1-\rho) i_{t}^{*}
$$


where $\rho$ is a parameter that measures the degree of interest rate smoothing.

We estimate different rules for the pre-Volcker (60:1-79:2) and Volcker-Greenspan (79:3-96:4). We do so because it is widely believed that U.S. monetary policy took an important turn for the better with the appointment of Paul Volcker as Fed Chairman (see Friedman and Kuttner (1996) and Gertler (1996)). Among other things, this period marks the beginning of an apparently successful and long lasting disinflation.

We find that the simple rule given by equation (7.2) does a good job of characterizing policy in the Volcker-Greenspan era. Further, it adheres to the guidelines for good policy that we have established. The estimated pre-Volcker rule violates these guidelines. Specifically, the parameter estimates along with standard errors are given by ${ }^{79}$

\section{Table 1: Estimates of Policy Reaction Function}

$\begin{array}{cccc} & \gamma_{\pi} & \gamma_{x} & \rho \\ \text { Pre-Volcker } & 0.80 & 0.52 & 0.76 \\ & (0.09) & (0.12) & (0.04) \\ \text { Volcker-Greenspan } & 1.96 & 0.07 & 0.66 \\ & (0.20) & (0.10) & (0.03)\end{array}$

The key lesson involves the parameter $\gamma_{\pi}$, the coefficient on the inflation gap. The estimate for the pre-Volcker rule is significantly less than unity. This suggests

\footnotetext{
${ }^{79}$ The estimates of the parameters in equation (7.2) are obtained by using an instrumental variables procedure based on Generalized Methods of Moments (GMM). See Clarida, Gali and Gertler (1997) for details. The specific numbers reported here are based on a version of this policy reaction function that has the Funds rate respond to expected inflation a year ahead and the current output gap (reported in Table 2 of that paper). The results, however, are robust to reasonable variations in the horizons for the gap variables.
} 
that monetary policy over this period was accommodating increases in expected inflation, in clear violation of the guidelines suggested by Results 2 and 3. For the post-1979 rule the estimate is significantly above unity. It thus incorporates the implicit inflation targeting feature that we have argued is a critical feature of good monetary policy management. It is also true that in the Volcker-Greenspan era the Federal Reserve was only responding to the output gap to the extent it had predictive power for inflation: ${ }^{80}$ The estimated coefficient on the output gap, $\gamma_{x}$, is not significantly different from zero. Pre 1979:4 it is positive and significant. This outcome is consistent with the conventional view that pre-1979, the Federal Reserve was relatively more focused on output stabilization and less focused on inflation.

The finding that the Fed responded differently to inflation in the two eras is apparent from inspection of the data. Figure 4 plots the Federal Funds rate and the rate of CPI inflation from 1965 to the present. The graph shows a clear break in the Funds rate process around $1979 .{ }^{81}$ During most of the 1970 s, the ex post real rate was zero or negative. After 1979 it becomes positive. While many factors influence the real rate, the tight monetary policy engineered by Paul Volcker surely provides the most logical explanation for this initial run-up.

Figure 5 illustrates the policy change by plotting the estimated target value of the interest rate under the Volcker-Greenspan rule over the entire sample period. The target rule does a good job of capturing the broad movements in the Funds rate for the second half of the sample, for which it was estimated. For the pre-

\footnotetext{
${ }^{80}$ In particular, the output gap enters the instrument set for expected inflation. Thus, the coefficent $\gamma_{x}$ reflects the influence of the output gap on the interest rate that is independent of its predictive power for inflation.

${ }^{81}$ Huizinga and Mishkin (1986) present formal evidence of a structural break at this time.
} 
Volcker period, matters are different. The target (generated by the estimated Volcker-Greenspan rule) is systematically well above the historical series. In this concrete respect, policy was far less aggressive in fighting inflation in the earlier period.$^{82}$

Figure 6 compares the ability of the forward and backward looking (Taylor) target rules to explain the post 1979 data. Though we find that the data rejects the backward looking rule in favor of the forward looking one, ${ }^{83}$ the two do a roughly similar job of accounting for the behavior of the Funds rate. This occurs probably because, with U.S. data, not much besides lagged inflation is useful for predicting future inflation.

Finally, it is interesting to observe that the other major central banks, the Bundesbank and the Bank of Japan, have behaved very similarly in the post-1979 era. In Clarida, Gali and Gertler (1998), we estimate our specification for these central banks. The estimated parameters in each case are quite close to those obtained for the Federal Reserve during the Volcker-Greenspan period. Thus, good policy management appears to have been a global phenomenon. Perhaps this is not surprising since the successful disinflation has also been a world-wide event.

\subsection{Simple Target Rules}

There have also been proposed simple rules for targets, as opposed to instruments. Of these proposed policies, inflation targeting has received by far the most atten-

\footnotetext{
${ }^{82}$ Some but not nearly all the difference between rates pre-1979 and the target vaules under a post-1979 rule could be accounted for a secular change in the real rate.

${ }^{83}$ See Clarida, Gali and Gertler (1998).
} 
tion (see Bernanke and Mishkin (1997), for a recent survey). Indeed a number of central banks, most notably the Bank of England, have recently adopted formal inflation targets (see, e.g., Andrew Haldane, (1996)).

In one sense, inflation targeting involves nothing more than pursuing the kind of gradualist policy that our optimal policy calculation implies (see Result 2). Indeed, all the leading real-world proposals call for gradual convergence of inflation to target. None recommend trying to hit the inflation target continuously, which is consistent with our analysis. In this respect, the rule we estimate for the period is perfectly consistent with inflation targeting.

The rationale for inflation targeting, we think, is twofold. The first is simply to guarantee that monetary policy avoids the mistakes of the pre-Volcker era by identifying a clear nominal anchor for policy. (After all, Alan Greenspan will not be around forever). The inflation target is in effect the nominal anchor. Since the anchor is directly in terms of inflation, it avoids the potentially instability problems associated with alternatives such as money growth that are only indirectly linked to inflation. For example, if there are large shocks to money demand, then a money growth target may fail precisely to pin down the equilibrium inflation rate.

The second rationale has to do with credibility and commitment. We have seen that it is in general optimal for policy-makers to place a higher weight on the costs of inflation than the true social loss function suggests (see Results 6 and 7). The focus on inflation targets may be viewed as a way to instill a higher effective weight on inflation in the policy choice.

Price level targeting is another type of simple rule that has been discussed in the literature. This policy, which may be thought of as a more extreme version 
of inflation targeting, has not received much support among policy-makers and applied economists. There are several problems: First, if the price level overshoots its target, the central bank may have to contract economic activity in order to return the price level to its goal. That is, inflation above the amount implied by the price level target must be followed by inflation below this desired amount in order to return the target. Under inflation targeting, bygones are bygones: overshooting of inflation in one year does not require forcing inflation below target in the following year. Second, the source of positive drift in the price level may be measurement error (see the discussion in section 2.) It would be unfortunate to have measurement error induce tightening of monetary policy. Third, as McCallum (1997b) shows, the net reduction in price uncertainty under a price level target rule, may be small relative that obtained under an inflation targeting policy. For all these reasons, it is perhaps not surprising that no major central bank has adopted a price level target.

Another candidate variable for targeting is nominal GDP. This approach has also received less attention in the recent literature, however. One problem is that if there are shifts in the trend growth of real GDP, the rule does not provide a precise nominal anchor. Another problem, emphasized by Ball (1997), is that the policy may be overly restrictive. In the hybrid model of section 5 , for example, the optimal policy in general has the interest rate adjust to some linear combination of expected inflation, the output gap and demand disturbances. The weights depend upon the underlying structural parameters of the model. Under nominal GDP targeting, the central bank adjusts the interest rate to the sum of inflation and real GDP growth. It thus arbitrarily applies an equal weight to each component of nominal GDP. High nominal GDP growth, further, could occur when the economy 
is recovering from a recession and is still well below full capacity. A rule that calls for raising interest rates in response to above target nominal GDP growth in these circumstances could stifle the recovery. ${ }^{84}$

\subsection{Indeterminacy under Interest Rate Rules}

One criticism of simple interest rate rules is that, under certain circumstances, they may induce instability. That is, in many models there may not be a determinate equilibrium under particular parametrizations of the policy rule. In a classic paper, Thomas Sargent and Neil Wallace (1975), illustrated how nominal indeterminacy may arise if prices are perfectly flexible. Under an interest rate rule the equilibrium pins down the level of real money balances. However, there are an infinite number of combinations of the nominal money stock and the price level that satisfy this equilibrium condition. ${ }^{85}$ In this respect, the interest rate rule produces nominal indeterminacy. ${ }^{86}$

When there is sluggish price adjustment, the problem of nominal indeterminacy vanishes. Last period's price level effectively serves a nominal anchor. Simple interest rate rules thus do not produce price level indeterminacy in the frameworks we have analyzed. More generally, since there is little reason to believe that prices are perfectly flexible, the issue of nominal indeterminacy does not seem important

\footnotetext{
${ }^{84}$ See Ball (1997) and Svensson (1997b) for explicit examples of how nominal GDP targeting could produce adverse outcomes. McCallum (1997c), however, argues that these results are sensitive to the use of a backward looking Phillips curve. For the case in favor of nominal GDP targeting, see Hall and Mankiw (1994).

${ }^{85}$ McCallum (1997), however, argues that the price level is in fact determined in this kind of environment.

${ }^{86} \mathrm{~A}$ recent literature shows that the government's intertemporal budget constraint may restore uniqueness under an interest rule, even in an environment with flexible prices. What is critical is whether the interest on the debt is financed by taxes or money creation. See, for example, Woodford (1994), Sims, (1994), and Leeper (1991).
} 
in practice.

On the other hand, there is potentially a problem of real indeterminacy in the case of price stickiness, as William Kerr and Robert King (1996), Bernanke and Woodford (1997) and Clarida, Gali and Gertler (1997) have recently emphasized. ${ }^{87}$ Two types of indeterminacy are possible. First, if in response to a rise in expected inflation, the nominal rate does not increase sufficiently to raise the real rate, then self-fulfilling bursts of inflation and output are possible. A rise in expected inflation, leads to a fall in real rates that, in turn, fuels the boom. Indeed, the monetary policy rule that Clarida, Gali and Gertler (1997) estimate for the preVolcker period permits exactly this kind of sunspot behavior. The lesson here is simply that a good monetary policy rule should not accommodate rise in expected inflation. It should instead pursue the implicit kind of inflation targeting that we have been emphasizing. This boils down to raising nominal rates sufficiently to increase real rates whenever expected inflation goes up.

As Bernanke and Woodford (1998) emphasize, indeterminacy is also possible if the rule calls for an overly aggressive response of interest rates to movements in expected inflation. In this instance, there is a "policy overkill" effect that emerges that may result in an oscillating equilibrium. Clarida, Gali and Gertler (1997) show, however, the magnitude of the policy response required to generate indeterminacy of this type greatly exceeds the estimates obtained in practice. This potential indeterminacy however does suggest another reason why a gradual

\footnotetext{
${ }^{87}$ These papers focus on local indeterminacy. See Benhabib, Schmidt-Grohe, and Uribe (1998) for a discussion of global indeterminacy. To avoid global indeterminacy, the central bank may have to commit to deviate from a simple interest rate rule if the economy were to get sufficiently off track. This threat to deviate can be stabilizing, much the way off the equilibrium path threats induce uniqueness in game theory. Because the threat is sufficient to preclude indeterminate behavior, further, it may never have to be implemented in practice.
} 
approach to meeting an inflation target may be desirable.

\section{Concluding Remarks}

We conclude by describing several areas where future research would be quite useful:

(1) It is always the case that more knowledge of the way the macroeconomy works can improve the performance of monetary policy. Particularly critical, however, is a better understanding of the determinants of inflation. As we have emphasized, the output/inflation trade-off is highly sensitive to both the degree and nature of the persistence in inflation. As a consequence, so too is the speed at which monetary policy should try to reach the optimal inflation rate. Rationalizing the observed persistence in inflation is thus a high priority. Work by Gali and Gertler (1998) and Argia Sbordone (1998) suggests that the short run aggregate supply curve employed in our baseline model may provide a reasonable approximation of reality, so long as real marginal cost (specifically real unit labor costs) is used as the relevant real sector forcing variable instead of the output gap, as the theory suggests. Gali and Gertler (1998) argue further that persistence in inflation may be related to sluggish adjustment of unit labor costs vis-a-vis movements in output. Sorting out this issue will have important repercussions for monetary policy.

(2) Our analysis of monetary policy, as in much of the literature, was restricted to closed economy models. Extensions to open economy frameworks are likely to provide new insights on the desirability of alternative monetary policy rules, and raise a number of issues of great interest, including: the choice of exchange rate 
regime, the potential benefits from monetary policy coordination, the optimal response to shocks originating abroad, and consumer price index versus domestic inflation targeting. Recent work by Ball (1998), Svensson (1998) and Monacelli (1999) along these lines will undoubtedly lay the ground for further research on this front.

(3) Throughout the analysis, we assumed that the lower bound of zero on the nominal interest rate was not a constraint on the performance of monetary policy. In Japan, for example, the short term nominal rate has fallen to the point where this constraint clearly is a consideration for policy management. Similarly, in the U.S. and Europe, the inflation rates have fallen to the point where the zero bound limit could conceivable affect the ability to ease rates in the event of a downturn. Understanding how monetary policy should proceed in this kind of environment is an important task. When the nominal rate is at zero, the only way a central bank can reduce the real interest rate is to generate a rise in expected in inflation (see the discussion in Alexander Wolman, 1998, and the references therein.) How the central bank should go about this and whether cooperation from fiscal policy is necessary are important open questions. As Wolman (1998) suggests, the conclusions are quite sensitive to the nature of the inflationary process.

(4) A more specific issue, but nonetheless an important one, is to understand why central banks smooth interest rate adjustments. As we discussed in section 5, optimal policies implied by most existing macroeconomic frameworks generate paths for the interest rate that are much more volatile than what is observed in reality. The possibility thus arises that existing models may fail to adequately characterize the constraints that policy-makers face in practice. We suggested in 
section 5 that some form of model uncertainty might be able to account for this phenomenon. Another alternative, is that central banks may be exploiting the dependency of demand on expected future interest rates, as argued by Rotemberg and Woodford (1998). Whether these explanations or any others, such as fear of disruption of financial markets, can account for interest rate smoothing needs to be determined.

(5) A somewhat related issue involves how a central bank should deal with financial stability. The policy rules discussed in the literature do include contingencies for financial crises. A frequently cited reason for why monetary policy should not adhere tightly to a simple rule is the need for flexibility in the event of a financial collapse. In the wake of the October 1987 stock market crash, for example, most economists supported the decision of the Federal Reserve Board to reduce interest rates. This support was based largely on instinct, however, since there is virtually no formal theoretical work that rationalizes this kind of intervention. More generally, concern about financial stability appears to be an important constraint on policy-making. As we suggested in section 5, it is one possible reason why central banks smooth interest rate changes. Understanding the nature of this concern is clearly a fertile area for research.

(6) Finally, with few exceptions, virtually all the literature ignores the issue of transition to a new policy regime. ${ }^{88}$ In particular, the rational expectations assumption is typically employed. Policy simulations thus implicitly presume that the private sector catches on immediately to any regime change. In reality, however, there may be a period of transition where the private sector learns about

\footnotetext{
${ }^{88}$ An exception is Brayton, Levin Tyron and Williams (1997) who present simulations of policy regime chnages under different assumptions about the behavior of private sector expectations.
} 
the regime change. This kind of scenario may be highly relevant to a central bank that has accommodated inflation for a sustained period of time but is intent on embarking on a disinflation. Modeling private sector learning is a challenging but nonetheless important task. Sargent (1999) provides a promising start in this direction. More work along these lines would be highly desirable. 


\section{Appendix: The General Solution Under Commitment}

At time $t$,the central bank commits to a state contingent sequence for $x_{t+i}$ and $\pi_{t+i}$ to maximize

$$
\max -\frac{1}{2} E_{t}\left\{\sum_{t=o}^{\infty} \beta^{t}\left[\alpha x_{t+i}^{2}+\pi_{t+i}^{2}\right]\right\}
$$

subject to the short run aggregate supply curve

$$
\pi_{t+i}=\lambda x_{t+i}+\beta E_{t}\left\{\pi_{t+1+i}\right\}+u_{t+i}
$$

with

$$
u_{t+i}=\rho u_{t+i-1}+\varepsilon_{t+i}
$$

Following Currie and Levine (1993) and Woodford (1998), form the Lagrangian:

$$
\max -\frac{1}{2} E_{t}\left\{\sum_{i=o}^{\infty} \beta^{i}\left\{\left[\alpha x_{t+i}^{2}+\pi_{t+i}^{2}\right]+\phi_{t+i}\left[\pi_{t+i}-\lambda x_{t+i}-\beta \pi_{t+1+i}-u_{t+i}\right]\right\}\right\}
$$

where $\frac{1}{2} \phi_{t+i}$ is the multiplier associated with the constraint at $t+i$.

The first order necessary conditions yield:

$$
\alpha x_{t+i}-\frac{\lambda}{2} \phi_{t+i}=0, \quad \forall i \geq 0
$$




$$
\begin{aligned}
\pi_{t+i}+\frac{1}{2} \phi_{t+i}-\frac{1}{2} \phi_{t+i-1} & =0, \quad \forall i \geq 1 \\
\pi_{t}+\frac{1}{2} \phi_{t} & =0
\end{aligned}
$$

Combining the first order necessary conditions to eliminate $\phi_{t+i}$ then yields the optimality conditions

$$
\begin{aligned}
x_{t+i}-x_{t+i-1} & =-\frac{\lambda}{\alpha} \pi_{t+i}, \quad \forall i \geq 1 \\
x_{t} & =-\frac{\lambda}{\alpha} \pi_{t}
\end{aligned}
$$

Substituting the optimality conditions in the aggregate supply curve to eliminate $\pi_{t+i}$ then yields a stochastic difference equation for $x_{t}$ :

$$
x_{t}=a x_{t-1}+a \beta E_{t}\left\{x_{t+1}\right\}-\frac{\lambda a}{\alpha} u_{t}
$$

where $a \equiv \frac{\alpha}{\alpha(1+\beta)+\lambda^{2}}$. The stationary solution to this difference equation is given by:

$$
x_{t}=\delta x_{t-1}-\frac{\lambda \delta}{\alpha(1-\delta \beta \rho)} u_{t}
$$

where $\delta \equiv \frac{1-\sqrt{1-4 \beta a^{2}}}{2 a \beta} \in(0,1)$, implying the process for $x_{t}$ is stable. Substituting the solution for $x_{t}$ in the aggregate supply curve then yields a solution for $\pi_{t}$.

$$
\pi_{t}=\delta \pi_{t-1}+\frac{\delta}{(1-\delta \beta \rho)}\left(u_{t}-u_{t-1}\right)
$$


Since $\pi_{t}=p_{t}-p_{t-1}$, the solution implies a stationary process for the price level :

$$
p_{t}=\delta p_{t-1}+\frac{\delta}{(1-\delta \beta \rho)} u_{t}
$$

The stationary behavior of the price level results from the fact that the optimality condition effectively has the central bank adjust demand in response to movements in the price level relative to trend. Given $\pi_{t}=p_{t}-p_{t-1}$, the optimality condition may be expressed as

$$
x_{t+i}=-\frac{\lambda}{\alpha} p_{t+i} \quad \forall i \geq 1
$$

Thus, for example, the central bank contracts demand when the price level rises above trend: hence, the trend-reverting behavior of the price level. 


\section{References}

[1] Aiyagari, Rao S., and R. Anton Braun, 1998, "Some Models to Guide the Fed", Carnegie-Rochester Conference Series on Public Policy 48, June, pp.1-42.

[2] Ball, Laurence, 1995, "Disinflation with Imperfect Credibility," Journal of Monetary Economics 35, pp.5-23.

[3] Ball, Laurence, 1997, "Efficient Rules for Monetary Policy", 1997, NBER Working Paper No. 5952, March.

[4] Ball, Laurence, 1998, "Policy Rules for Open Economies," NBER WP\# 6760.

[5] Barro, Robert J. and David B. Gordon, 1983, "A Positive Theory of Monetary Policy in a Natural Rate Model, Journal of Political Economy 91, pp. 589-610.

[6] Benhabib, Jess, Stephanie Schmitt-Grohe, and Martin Uribe, 1998, "The Perils of Taylor Rules," mimeo, New York University.

[7] Bernanke, Ben S. and Alan Blinder, 1992, "The Federal Funds Rate and the Transmission of Monetary Policy," American Economic Review 82: pp.90121

[8] Bernanke, Ben. S. and Mark Gertler, 1995, "Inside the Black Box: The Credit Channel of Monetary Policy Transmission," Journal of Economic Perspectives 9 no.2, Fall, 27-48. 
[9] Bernanke, Ben. S., Mark Gertler and Simon Gilchrist, 1998, "The Financial Accelerator in a Quantitative Business Cycle Framework," NBER Working Paper No. 6455, March, forthcoming in The Handbook of Macroeconomics, John Taylor and Michael Woodford, eds.

[10] Bernanke, Ben S., Mark Gertler and Mark Watson, 1997, "Systematic Monetary Policy and The Effects of Oil Price Shocks," Brookings Papers on Economic Activity 2, (Spring), pp. 91-157.

[11] Bernanke, Ben S., and Ilian Mihov, 1997, "What Does the Bundesbank Target?", European Economic Review 41, June, pp. 1025-1054.

[12] Bernanke, Ben S., and Ilian Mihov, 1998, "Measuring Monetary Policy", Quarterly Journal of Economics, CXIII, August, pp. 869-902.

[13] Bernanke, Ben S. and Frederic Mishkin, 1997, "Inflation Targeting: A New Framework for Monetary Policy?", Journal of Economic Perspectives 9, Spring, pp. 97-116.

[14] Bernanke, Ben S., and Michael Woodford, 1997, "Inflation Forecasts and Monetary Policy", Journal of Money, Credit and Banking,

[15] Blanchard, Olivier J., 1997, Macroeconomics, Prentice-Hall, Upper Saddle River, New Jersey.

[16] Blinder, Alan S., 1997, "What Central Bankers Can Learn from Academics - and Vice-Versa," Journal of Economic Perspectives 11, Spring, 3-20. 
[17] Bomfin, Antulio N., and Glenn D.Rudebusch, 1997, "Opportunistic and Deliberate Disinflation Under Imperfect Credibility," mimeo, Federal Reserve Bank of San Francisco, July.

[18] Brainard, William C., 1967, "Uncertainty and the Effectiveness of Policy," American Economic Review 57, May, pp. 411-25.

[19] Brayton, Flint, Andrew Levin, Ralph Tryon, and John C. Williams, 1997, "The Evolution of Macro Models at the Federal Reserve Board," Finance and Economics Discussion Paper Series No. 1997-29, Federal Reserve Board, June.

[20] Calvo, Guillermo, 1983, "Staggered Prices in a Utility Maximizing Framework," Journal of Monetary Economics, 12, pp. 383-398.

[21] Campbell, John Y., 1995, "Some Lessons from the Yield Curve," Journal of Economic Perspectives 9, Summer, pp. 129-52.

[22] Carlstrom, Charles T., and Timothy S. Fuerst, 1995, "Interest Rate Rules vs. Money Supply Rules: A Welfare Comparison in a Cash-in-Advance Model, Journal of Monetary Economics, pp.247-268.

[23] Chari, V.V., Lawrence J. Christiano, and Martin Eichenbaum, 1998, "Expectation Traps and Discretion," Journal of Economic Theory.

[24] Christiano, Lawrence J. and Christopher J. Gust, 1999, "Taylor Rules in a Limited Participation Model," NBER Working Paper No. 7017. 
[25] Christiano, Lawrence J., Martin Eichenbaum and Charles Evans, 1996, "The Effects of Monetary Policy Shocks: Evidence from the Flow of Funds", Review of Economics and Statistics 78 (February): pp. 16-34.

[26] Christiano, Lawrence J., Martin Eichenbaum and Charles Evans, 1997, "Sticky Price and Limited Participation Models of Money: A Comparison," European Economic Review 41, pp. 1201-1241.

[27] Christiano, Lawrence J., Martin Eichenbaum and Charles Evans, 1998, "Monetary Policy Shocks: What Have We Learned and to What End?", NBER Working Paper No. 6400.

[28] Clarida, Richard and Mark Gertler, 1997, "How the Bundesbank Conducts Monetary Policy," in Reducing Inflation: Motivation and Strategy, Christina and David Romer editors, NBER, Chicago, pp. 363-412.

[29] Clarida, Richard, Jordi Gali and Mark Gertler, 1997, "Monetary Policy Rules and Macroeconomic Stability: Evidence and Some Theory," NBER Working Paper No. 6442.

[30] Clarida, Richard, Jordi Gali and Mark Gertler, 1998, "Monetary Policy Rules in Practice: Some International Evidence," European Economic Review, XLII, pp. 1033-1068.

[31] Currie, David and Paul Levine, 1993, Rules, Reputation and Macroeconomic Policy Coordination, Cambridge: Cambridge University Press. 
[32] DeLong, J. Bradford “America's Peacetime Inflation: The 1970s," 1997, in Reducing Inflation: Motivation and Strategy, Christina and David Romer editors, NBER, Chicago, pp. 247-280.

[33] Erceg, Christopher J., Dale W. Henderson, and Andrw T. Levin, 1998, "Output-Gap and Price Volatilities: Reaffirming Tradeoffs in an Optimizing Model, mimeo, Federal Reserve Board.

[34] Estrella, Arturo, and Frederic S. Mishkin, 1997, "Is There a Role for Monetary Aggregates in the Conduct of Monetary Policy?", Journal of Monetary Eocnomics 41, October, pp. 279-304.

[35] Estrella, Arturo, and Frederic S. Mishkin, 1998, "Re-Thinking the Role of NAIRU in Monetary Policy: Implications of Model Formulation and Uncertainty," forthcoming in Monetary Policy Rules, edited by John B. Taylor?.

[36] Faust, John and Lars E.O. Svensson, 1998, "Credility and Transparency: Monetary Policy with Unobseravble Goals," mimeo, Federal Reserve Board.

[37] Feldstein, Martin S., 1997, "The Costs and Benefits of Going from Low Inflation to Price Stability," in Reducing Inflation: Motivation and Strategy, Christina and David Romer editors, NBER, Chicago, pp. 123-66.

[38] Feldstein, Martin and James H. Stock, 1996, "Measuring Money Growth when Financial Markets are Changing," Journal of Monetary Economics 37, February, pp. 3-28.

[39] Fischer, Stanley, "Modern Approaches to Central Banking", 1995, NBER Working Paper No. 5064, March 
[40] Friedman, Benjamin M., 1990, "Targets and Instruments of Monetary Policy," in Handbook of Monetary Economics, edited by Benjamin M. Friedman and Frank Hahn, Amsterdam, North Holland.

[41] Friedman, Benjamin M., and Kenneth N. Kuttner, 1996, "A Price Target for U.S. Monetary Policy? Lessons from the Experience with Money Growth Targets", Brookings Papers on Economic Activity, 1: pp 77-146.

[42] Fuhrer, Jeffrey C., 1996, "Towards a Compact, Empirically-Verified Rational Expectations Model for Monetary Policy Analysis", mimeo, November.

[43] Fuhrer, Jeffrey C., 1997a, "Inflation/Output Variance Trade-Offs and Optimal Monetary Policy", Journal of Money Credit and Banking, Vol 29, No. 2, May., pp 214-23

[44] Fuhrer, Jeffrey C., 1997b, "The (Un)Importance of Forward_Looking behavior in Price Setting," Journal fo Money, Credit and Banking 29, August, pp. 338-50.

[45] Fuhrer, Jeffrey C., and George R. Moore, 1995a, "Inflation Persistence", Quarterly Journal of Economics, No. 440, February, pp 127-159.

[46] Fuhrer, Jeffrey C., and George R. Moore, 1995b, " Monetary Policy Tradeoffs and the Correlation between Nominal Interest Rates and Real Output", American Economic Review, Vol. 85, No. 1, March , pp 219-239.

[47] Gali, Jordi, "How Well Does the IS/LM Model Fit Post-War U.S. Data?," 1992, Quarterly Journal of Economics 92, pp. 709-738. 
[48] Gali, Jordi and Mark Gertler, 1998, "Inflation Dynamics: A Structural Econometric Analysis," mimeo, New York University.

[49] Gali, Jordi and Mark Gertler, 1999, "Rules vs. Discretion Revisited: The Gains from Commitment in the Absence of an Inflationary Bias," work in progress.

[50] Gertler, Mark, 1996, "Comments on Friedman and Kuttner " Brookings Papers on Economic Activity, vol. 1, pp. 77-125.

[51] Goodfriend, Marvin, 1991, "Interest Rates and the Conduct of Monetary Policy", Carnegie-Rochester Conference Series on Public Policy, No. 34, 1991, pp 7-37.

[52] Goodfriend, Marvin and Robert G. King, 1997, "The New Neoclassical Synthesis and the Role of Monetary Policy," NBER Macroeconomics Annual, Ben Bernanke and Julio Rotemberg editors..

[53] Gordon, Robert J., 1997, "The Time-Varying NAIRU and it s Implications for Economic Policy," Journal of Economic Perspectives 11, Winter, pp. $11-32$.

[54] Haldane, Andrew, 1995, Inflation Targeting, Bank of England.

[55] Hall, Robert E., 1997, "Comments on Shiller," Brookings Papers on Economic Activity, Spring, 219-223.

[56] Hall, Robert E., and N. Gregory Mankiw, 1994, "Nominal Income Targeting," in Monetary Policy, edited by N. Gregory Mankiw, Chicago, University of Chicago Press. 
[57] Henderson, Dale W. and Warren J.Mckibbon, 1993, "A Comparison of Some Basic Monetary Policy Regimes for Open Economies," Carnegie-Rochester Series on Public Policy, 39, pp. 221-317.

[58] Huizinga, John and Frederic S. Mishkin, 1986, "Monetary Policy Regime Shifts and the Unusual Behavior of Real Interest Rates," Carnegie Rochester Conference Series on Public Policy 24, pp. 231-274.

[59] Ireland, Peter N., 1996a, "The Role of Countercyclical Monetary Policy", Journal of Political Economy, Vol 104, No. 4, 1996, pp 704-723.

[60] Ireland, Peter N., 1996b, "Expectations, Credibility, and Time-Consistent Monetary Policy", mimeo, Rutgers, December.

[61] Jovanovic, Boyan and Masako Udea, "Contracts and Money," 1997, Journal of Political Economy 105. August, pp. 700-708.

[62] Kerr, William and Robert G. King, 1996, "Limits on Interest Rate Rules in the IS Model," Economic Quarterly, LXXXII, pp. 47-76.

[63] King, Robert G., and Alexander L. Wolman, 1996,: "Inflation Targeting in a St. Louis Model of the 21st Century" NBER Working Paper No. $550 \%$

[64] King, Robert G., and Alexander L. Wolman, 1998,: "What Should the Monetary Authority Do When Prices Are Sticky, forthcoming in Monetary Policy Rules, edited by John B. Taylor?

[65] Kydland, Finn E. and Edward C. Prescott, 1977, "Rules Rather Than Discretion: The Inconsistency of Optimal Plans," Journal of Political Economy 85, pp. 473-491. 
[66] Leeper, Eric M., 1991, 'Equilibria Under 'Active' and 'Passive' Monetary and Fiscal Policies", Journal of Monetary Economics, No. 27, 1991, pp 129147.

[67] Leeper, Eric M., Christopher Sims and Tao Zha, 1996, "What Does Monetary Policy Do?," Brookings Papers on Economic Activity 2, (Fall), pp. $1-63$.

[68] Lown, Cara S. and Robert Rich, 1997, "Is There and Inflation Puzzle?, Federal Reserve Bank of New York Economic Policy Review, 51-69.

[69] McCallum, Bennett T., 1988, "Robustness Properties of a Rule for Monetary Policy," Carnegie-Rochester Conference on Public Policy 29, pp. 173204.

[70] McCallum, Bennett T., 1997a, "Crucial Issues Concerning Central Bank Independence", Journal of Monetary Economics 39, June, pp. 99-112.

[71] McCallum, Bennett T., 1997b, "Issues in the Design of Monetary Policy Rules," NBER Working Paper No., 6016, April, also forthcoming in The Handbook of Macroeconomics.

[72] McCallum, Bennett T., 1997c, "The Alleged Instability of Nominal Income Targeting," NBER Working Paper No. 6291, November.

[73] McCallum, Bennett T., and Edward Nelson, 1997, "An Optimizing IS-LM Specification for Monetary Policy and Business Cycle Analysis", NBER Working Paper No. 5875, January. 
[74] Monacelli, Tommaso, 1999, "Into the Mussa Puzzle: Monetary Policy Regimes and the Real Exchange Rate in a Small Open Economy," mimeo, Boston College.

[75] Onatski Alexei, and James H. Stock, 1999, "Robust Monetary Policy Under Model Uncertainty in a Small Model of the U.S. Economy," mimeo, Harvard.

[76] Orphanides, Athanasios, 1998, "Monetary Policy Evaluation with Noisy Information," mimeo, Federal Reserve Board.

[77] Orphanides, Athanasios and David Wilcox, 1996, "The Opportunistic Approach to Disinflation," Finance and Economics Discussion Paper Series No. 96-24, Federal Reserve Board, May.

[78] Orphanides, Athanasios, David H. Small, Volker Weiland, and David W. Wilcox, 1997, "A Quantitative Exploration of the Opportunistic Approach to Disinflation", Finance and Economics Discussion Series, Federal Reserve Board, Washington D.C., No. 36, June.

[79] Persson, Torsten and Guido Tabellini, 1997, "Political Economics and Macroeconomic Policy," mimeo, Institute for International Economics, Stockholm.

[80] Poole, William, 1970, "Optimal Choice of Monetary Policy Instruments in a Simple Stochastic Macro Model," Quarterly Journal of Economics 84, pp. 197-216.

[81] Roberts, John M., 1997, "Is Inflation Sticky? ", Journal of Monetary Economics, No. 39, pp 173-196. 
[82] Rogoff, Kenneth, 1985, "The Optimal Degree of Commitment to an Intermediate Monetary Target," Quarterly Journal of Economics," 100, November, pp. 1169-89.

[83] Rogoff, Kenneth, 1987, "Reputational Constraints on Monetary Policy," Carnegie-Rochester Conference on Public Policy 26' Spring, 141-181.

[84] Romer, Christina D. and David H. Romer, 1989, "Does Monetary Policy Matter? A NEw Test in the Spirit of Friedman and Schwartz," NBER Macroeconomics Annual.

[85] Rotemberg, Julio, 1996, "Prices, Hours and Output: An Empirical Analysis Based on a Sticky Price Model," Journal of Monetary Economics 37, June, pp. 505-534.

[86] Rotemberg, Julio and Michael Woodford, 1997, "An Optimization-Based Econometric Framework for the Evaluation of Monetary Policy," NBER Macroeconomics Annual, Ben Bernanke and Julio Rotemberg eds.

[87] Rotemberg, Julio and Michael Woodford, 1998, "Interest Rate Rules in an Estimated Sticky Price Model," forthcoming in Monetary Policy Rules, edited by John B. Taylor?.

[88] Rudebusch, Glenn D., 1995, "Federal Reserve Interest Rate Targeting, Rational Expectations and the Term Structure," Journal of Monetary Economics 35: pp. 245-274.

[89] Rudebusch, Glenn D. and Lars Svensson, 1998, "Policy Rules for Inflation Targeting," forthcoming in Monetary Policy Rules, edited by John Taylor. 
[90] Sack, Brian, 1997a, "Uncertainty and Gradual Monetary Policy", mimeo, Federal Reserve Board, May.

[91] Sack, Brian, 1997b, "Does the Fed Act Gradually? A VAR Analysis", mimeo, Federal Reserve Board, May.

[92] Sargent, Thomas J., 1998, "The Conquest of American Inflation," mimeo.

[93] Sargent, Thomas J., 1999, "Comment on Ball," forthcoming in Monetary Policy Rules, edited by John B. Taylor.

[94] Sargent, Thomas J. and Neil Wallace, 1975 "Rational Expectations, the Optimal Monetary Instrument and the Optimal Money Supply Rule, Journal of Political Economy 83, pp. 241-254.

[95] Sbordone, Argia, 1998, "Prices and Unit Labor Costs: A New Test of Sticky Prices," mimeo, Rutgers University.

[96] Shiller, Robert J.,1997, "Public Resistance to Indexation: A Puzzle," Brookings Papers on Economic Activity, Spring, pp. 159-212.

[97] Sims, Christopher, 1994, "A Simple Model for the Determination of the Price Level and the Interaction of Monetary and Fiscal Policy," Economic Theory 4, pp. 381-399.

[98] Svensson, Lars E. O., 1997a, "Inflation Forecast Targeting: Implementing and Monitoring Inflation Targets", European Economic Review 41, June, pp. 1111-47. 
[99] Svensson, Lars E. O., 1997b, "Inflation Targeting: Some Extensions", NBER Working Paper No. 5962, March, forcthcoming in the Scandanavian Journal of Economics.

[100] Svensson, Lars E.O., 1997c, "Optimal Inflation Targets, 'Conservative Central Banks, and Linear Inflation Contracts," American Economic Review

[101] Svensson, Lars E.O., 1998, "Inflation Targeting as a Monetary Policy Rule," NBER Working Paper No. 6790, forthcoming in the Journal of Monetary Economics.

[102] Svensson, Lars E.O., 1998, "Open-Economy Inflation Targeting," mimeo, forthcoming in the Journal of International Economics.

[103] Svensson, Lars E.O., and Leonardo Leiderman, 1995, Inflation Targets, CEPR (London).

[104] Taylor, John B., 1979, "Estimation and Control of Macroeconomic Model with Rational Expectations," Econometrica, vol. 47, (September), pp. 126786.

[105] Taylor, John B., 1993a, "Discretion versus Policy Rules in Practice," Carnegie-Rochester Series on Public Policy 39, 195-214.

[106] Taylor, John B., 1998, Monetary Policy Rules, University of Chicago Press, forthcoming.

[107] Taylor, John B., 1998, "An Historical Analysis of Monetary Policy Rules," forthcoming in Monetary Policy Rules, edited by John B. Taylor. 
[108] Taylor, John B., 1993b, Macroeconomic Policy in a World Economy, New York: W.W. Norton.

[109] Theil, Henri, 1961, Economic Forecasts and Policy, 2nd edition, Amsterdam, North Holland.

[110] Tinbergen, Jan, 1952, On the Theory of Economic Policy, 2nd edition, Amsterdam, North Holland.

[111] Walsh. Carl, 1998, Monetary Theory and Policy, M.I.T. Press.

[112] Wieland, Volker, 1997, "Monetary Policy and Uncertainty about the Natural Unemployment Rate", mimeo, Federal Reserve Board, July.

[113] Williams, John C., 1997, "Simple Rules for Monetary Policy" , mimeo, Federal Reserve Board, June 1997.

[114] Wolman, Alexander, 1998, "Staggered Price Setting and the Zero Lower Bound on the Nominal Interest Rate," mimeo, Federal Reserve Bank of Richmond.

[115] Woodford, Michael, 1994a, "Nonstandard Indicators for Monetary Policy", in Monetary Policy, N. Gregory Mankiw editor, Chicago, University of Chicago Press: pp. 95-115.

[116] Woodford, Michael, 1994b, "Monetary Policy and Price Level Determinacy in a Cash-in-Advance Economy," Economic Theory 4, 345-380.

[117] Woodford, Michael, 1996, "Control of the Public Debt: A Requirement for Price Stability?", NBER Working Paper No. 5684, July. 
[118] Woodford, Michael, 1998, "Optimal Monetary Policy Inertia," mimeo, Princeton University.

[119] Yun, Tack, 1996, "Nominal Price Rigidity, Money Supply Endogeneity, and Business Cycles", Journal of Monetary Economics, No. 37, 1996, pp 345370. 
Fig 1: Efficient Policy Frontier for the

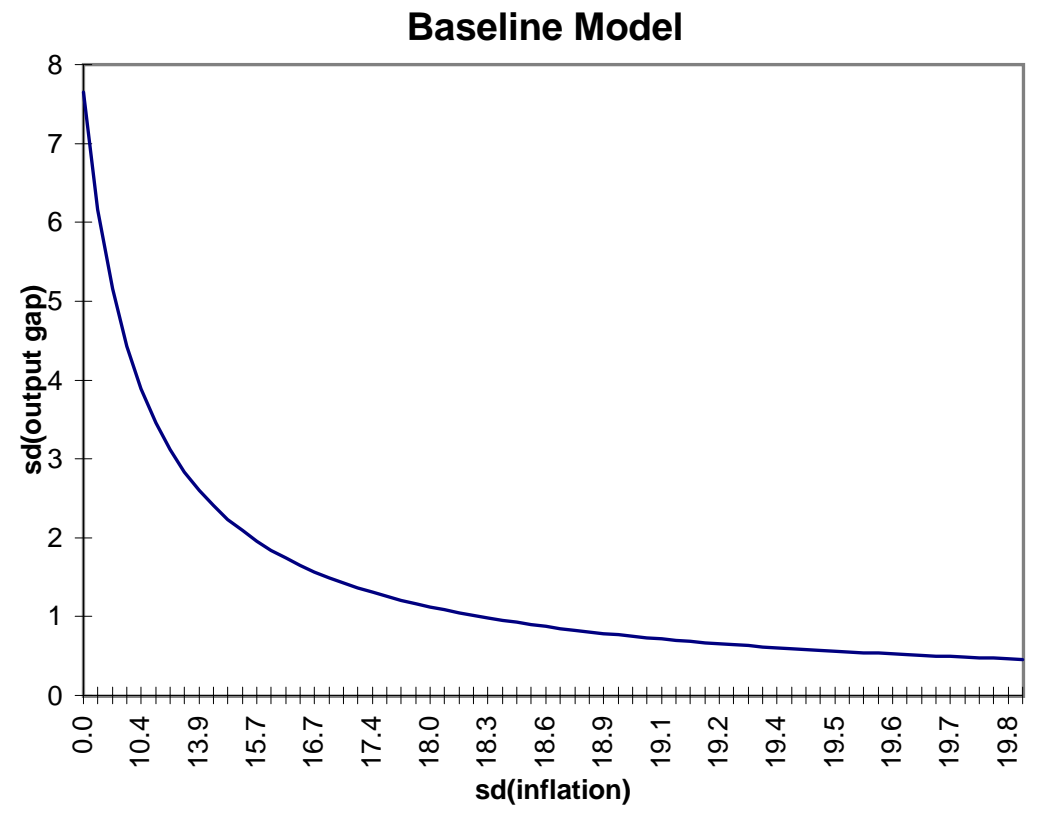

Fig 2: $a \pi$ for different values of $\phi$

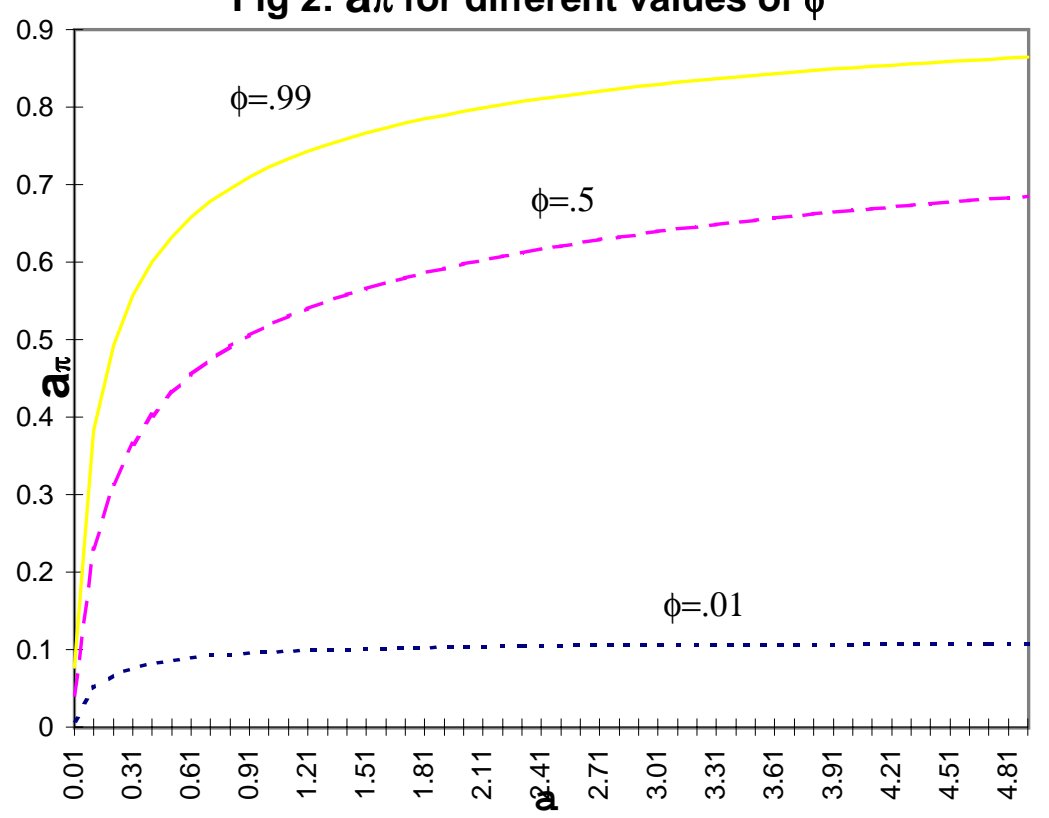


Fig 3: Efficient Policy Frontier for
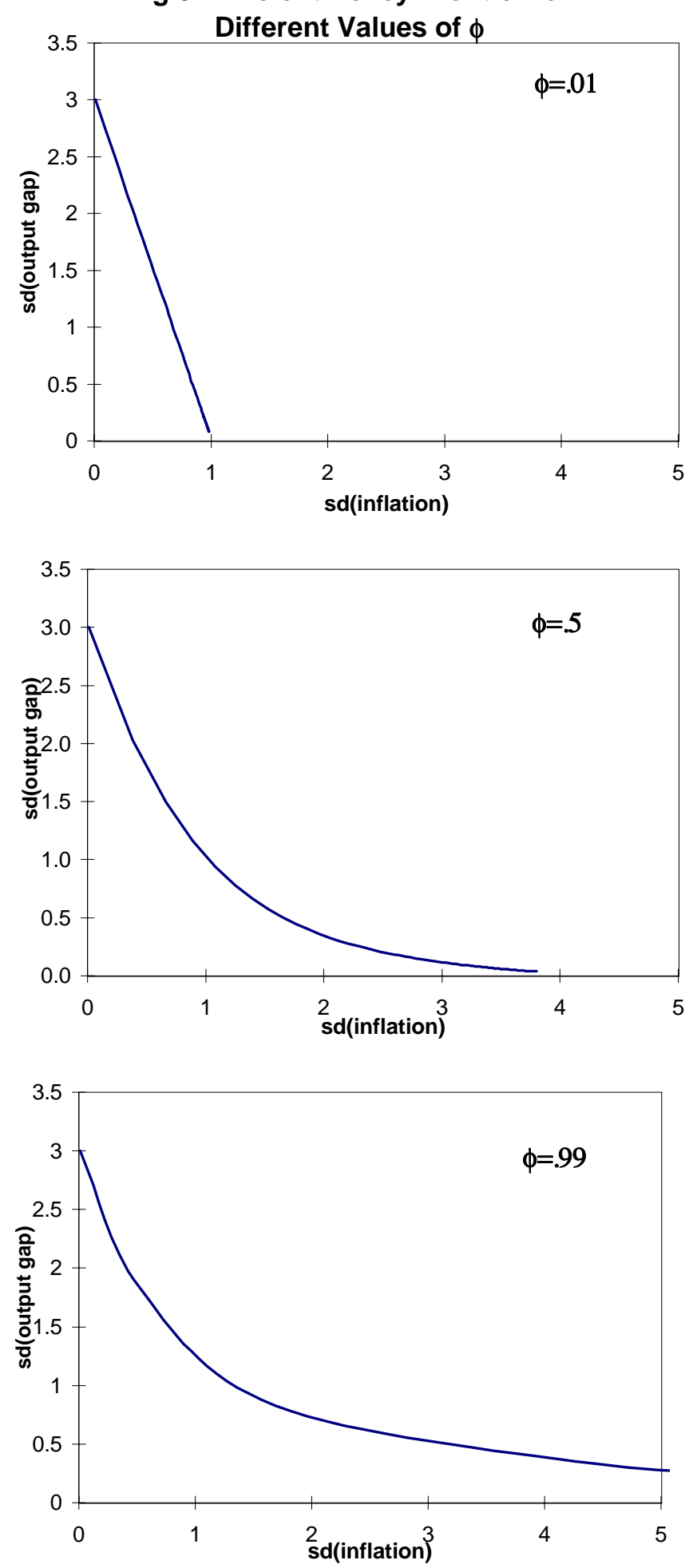


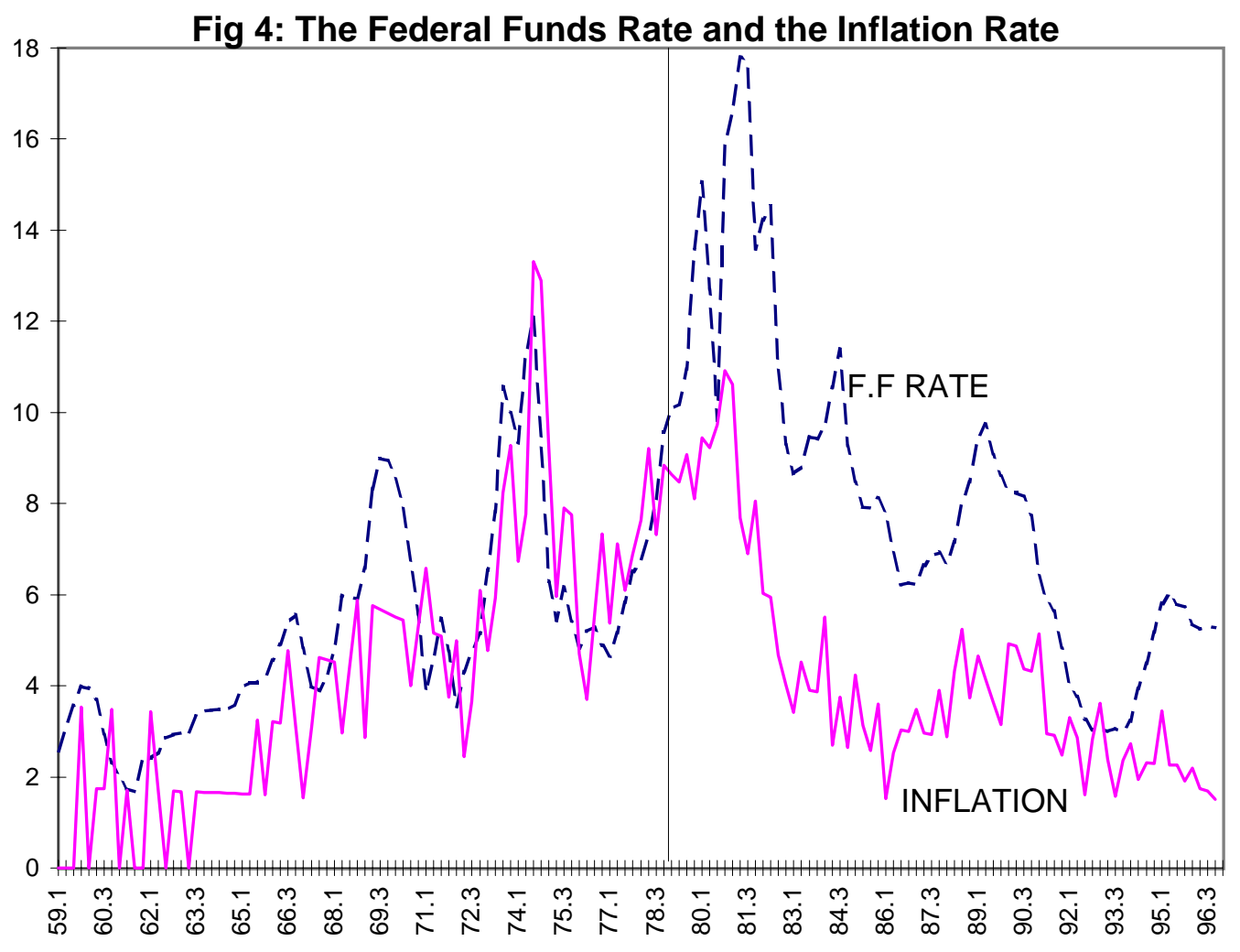


Fig 5: Target Based On Estimated Post-October '79 Rule

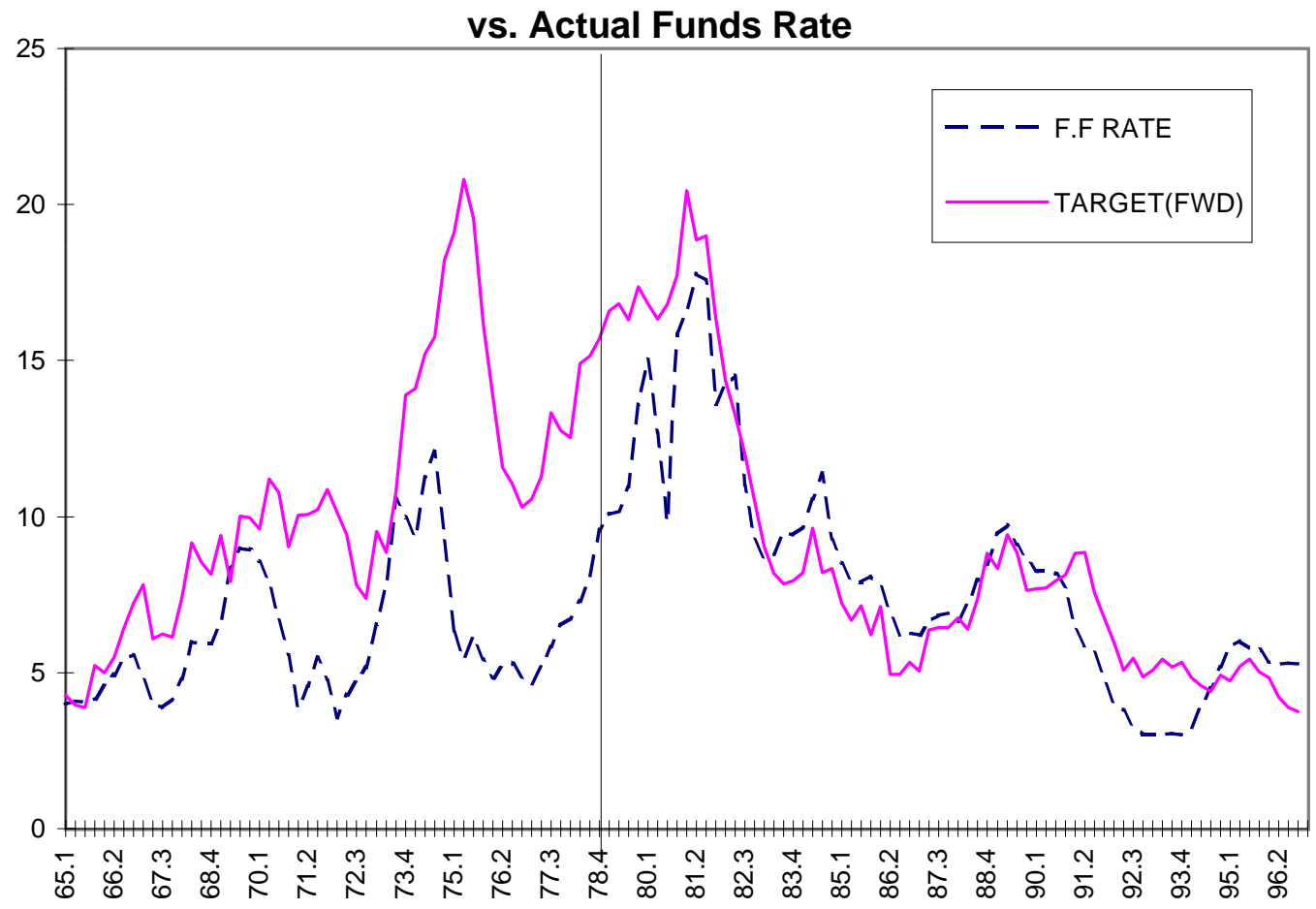

Fig 6: Targets from Forward vs. Backward Looking Rules

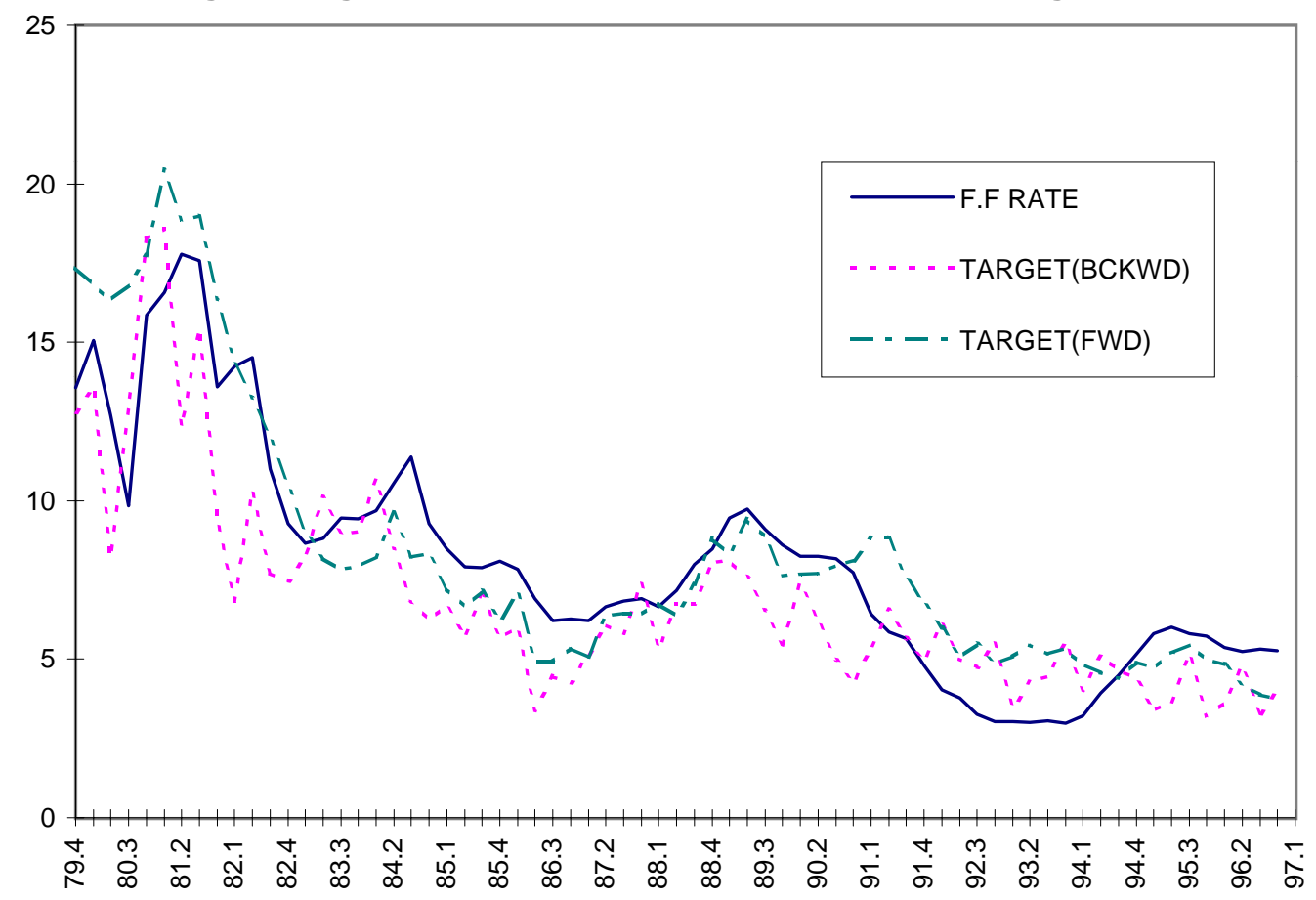

